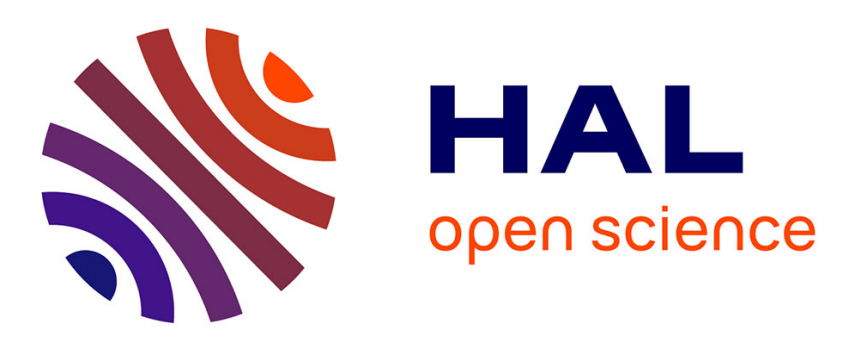

\title{
Genetic and immunobiological diversity of porcine reproductive and respiratory syndrome genotype I strains
}

Laila Darwich, Mariona Gimeno, Marina Sibila, Ivan Diaz, Eugenia de La Torre, Silvia Dotti, Liudmila Kuzemtseva, Margarita Martin, Joan Pujols, Enric Mateu

\section{To cite this version:}

Laila Darwich, Mariona Gimeno, Marina Sibila, Ivan Diaz, Eugenia de La Torre, et al.. Genetic and immunobiological diversity of porcine reproductive and respiratory syndrome genotype I strains. Veterinary Microbiology, 2011, 150 (1-2), pp.49. 10.1016/j.vetmic.2011.01.008 . hal-00687337

\section{HAL Id: hal-00687337 https://hal.science/hal-00687337}

Submitted on 13 Apr 2012

HAL is a multi-disciplinary open access archive for the deposit and dissemination of scientific research documents, whether they are published or not. The documents may come from teaching and research institutions in France or abroad, or from public or private research centers.
L'archive ouverte pluridisciplinaire HAL, est destinée au dépôt et à la diffusion de documents scientifiques de niveau recherche, publiés ou non, émanant des établissements d'enseignement et de recherche français ou étrangers, des laboratoires publics ou privés. 


\section{Accepted Manuscript}

Title: Genetic and immunobiological diversity of porcine reproductive and respiratory syndrome genotype I strains

Authors: Laila Darwich, Mariona Gimeno, Marina Sibila, Ivan Diaz, Eugenia de la Torre, Silvia Dotti, Liudmila Kuzemtseva, Margarita Martin, Joan Pujols, Enric Mateu

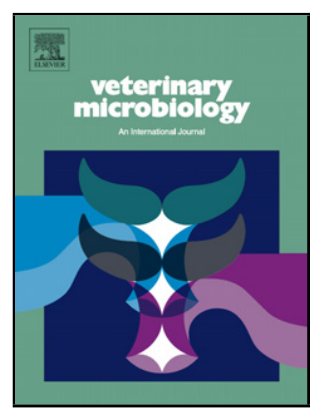

PII: S0378-1135(11)00012-5

DOI: doi:10.1016/j.vetmic.2011.01.008

Reference: $\quad$ VETMIC 5146

To appear in: $\quad$ VETMIC

Received date: $\quad 22-6-2010$

Revised date: $\quad 30-12-2010$

Accepted date: $\quad 10-1-2011$

Please cite this article as: Darwich, L., Gimeno, M., Sibila, M., Diaz, I., de la Torre, E., Dotti, S., Kuzemtseva, L., Martin, M., Pujols, J., Mateu, E., Genetic and immunobiological diversity of porcine reproductive and respiratory syndrome genotype I strains, Veterinary Microbiology (2010), doi:10.1016/j.vetmic.2011.01.008

This is a PDF file of an unedited manuscript that has been accepted for publication. As a service to our customers we are providing this early version of the manuscript. The manuscript will undergo copyediting, typesetting, and review of the resulting proof before it is published in its final form. Please note that during the production process errors may be discovered which could affect the content, and all legal disclaimers that apply to the journal pertain. 
1 Title: Genetic and immunobiological diversity of porcine reproductive and respiratory

2 syndrome genotype I strains.

3

4 Authors: Laila Darwich ${ }^{1,2}{ }^{*}$, Mariona Gimeno ${ }^{1,2 t}$, Marina Sibila ${ }^{2}$, Ivan Diaz ${ }^{2}$, Eugenia 5 de la Torre $^{2}$, Silvia Dotti ${ }^{2 \mathbb{I}}$, Liudmila Kuzemtseva ${ }^{2}$, Margarita Martin ${ }^{1,2}$, Joan Pujols ${ }^{2,3}$, 6 Enric Mateu $^{1,2}$

7

8 Affiliations:

91 Departament de Sanitat i Anatomia Animals, Universitat Autònoma de Barcelona, 1008193 Bellaterra, Spain.

112 Centre de Recerca en Sanitat Animal (CReSA), UAB-IRTA, campus UAB, 08193

12 Bellaterra, Spain.

133 Institut de Recerca i Tecnologia Agroalimentària (IRTA), Barcelona, Spain.

$14{ }^{\mathbb{I}}$ Current address: Instituto Zooprofilattico Sperimentale della Lombardia e dell'Emilia

15 Romagna "Bruno Ubertini"; Via Bianchi, 9; 25124 Brescia (Italy).

$16{ }^{\mathrm{t}} \mathrm{LD}$ and MG have contributed equally to this study.

17 *Corresponding author: Laila Darwich

18 e-mail: laila.darwich@uab.cat

19 Tel \#: +34935811046

$20 \quad$ Fax \#: +34935813297

21 
23 Genetic diversity of porcine reproductive and respiratory syndrome virus (PRRSV) has

24 been based on ORF5/GP5 and ORF7/N protein variations. Complete viral genome studies are limited and focused on a single or a few set of strains. Moreover, there is a general tendency to extrapolate results obtained from a single isolate to the overall PRRSV population. In the present study, six genotype-I isolates of PRRSV were sequenced from ORF1a to ORF7. Phylogenetic comparisons and the variability degree of known linear B-epitopes were done considering other available full-length genotype-I sequences. Cytokine induction of all strains was also evaluated in different cellular systems. Non structural protein 2 (nsp2) was the most variable part of the virus with 2 out of 6 strains harboring a 74 aa deletion. Deletions were also found in ORF3 and ORF4. Phylogenetic analyses showed that isolates could be grouped differently depending on the ORF examined and the highest similarity with the full genome cluster was found for the nsp9. Interestingly, most of predicted linear B-epitopes in the literature, particularly in nsp2 and GP4 regions, were found deleted or varied in some of our isolates. Moreover, 4 strains, those with deletions in nsp2, induced TNF- $\alpha$ and 3 induced IL-10. These results underline the high genetic diversity of PRRSV mainly in nsp1, nsp2 and ORFs 3 and 4. This variability also affects most of the known linear Bepitopes of the virus. Accordingly, different PRRSV strains might have substantially different immunobiological properties. These data can contribute to the understanding of PRRSV complexity.

44 Keywords: Porcine reproductive and respiratory syndrome virus; complete ORFs sequences; genotype-I; phylogenetic analyses; immunobiological properties. 
Porcine reproductive and respiratory syndrome virus (PRRSV) emerged in the last years of the decade of 1980s and by early 1990s became one of the major pathogens affecting the swine industry. At present, some 20 years after its emergence (Keffaber., 1989; Paton et al., 1991), PRRSV and the syndrome that it causes are still little understood and fully efficacious vaccines are lacking. The reasons for such a lack of vaccines are diverse but the high genetic diversity of the virus and the ability of PRRSV for subverting the immune response of the host are paramount. PRRSV is a positive-sense ssRNA enveloped virus classified within the genus Arterivirus. Nowadays, two genotypes are recognized (I and II) that originally were described as European and American because of the geographic origin of their prototypic strains (Lelystad virus and VR-2332), respectively (Collins et al., 1992; Wensvoort et al., 1991). Genetic diversity within genotype-I PRRSV isolates is high (Forsberg et al., 2002; Mateu et al., 2003; Stadejek et al., 2002) and at least three or four subtypes are being recognized (Stadejek et al., 2002, 2006, 2008).

PRRSV genome is organized in 9 open reading frames (ORF). ORF1a and 1b encode the viral replicase as well as other non structural proteins (nsp) (Snijder and Meulenberg., 1998).Of these nsp, nsp2 is the largest and has been shown to contain a large cluster of B-epitopes (Oleksiewicz et al., 2001). Recently, nsp2 and nsp1 of genotype II strains have been reported to be involved in the interplay between the virus and the host response (Beura et al., 2010; Chen et al., 2010, Subramaniam et al., 2010) by down-regulating mediation of interferons and other cytokines. ORFs $2 \mathrm{a}, 2 \mathrm{~b}$ and 3-7 encode for the viral structural proteins. Most of the abovementioned studies about 
genetic diversity of PRRSV have been developed by examining ORF5 or ORF7 but also some papers focused on ORF3 which is thought to be a molecular clock for PRRSV evolution (Forsberg et al., 2001). Surprisingly, a GenBank search for full length genome -or almost complete genome- PRRSV sequences of genotype I revealed the scarcity of these data and less than 10 full sequences could be found. The aim of the present study was to produce and analyze the sequence of ORFs 1a to 7 of contemporary PRRSV field strains of genotype-I for determining within genome diversity and phylogenetic relatedness and to examine some of the immunobiological properties associated with those strains.

\section{Material and methods}

. Strains and sequencing. Six field PRRSV strains (2982, 3249, 3256, 3262, 3266 and, 3267) were randomly selected among non epidemiological related strains. Additionally, the vaccine strain Porcilis PRRS was also sequenced. Origin and characteristics of these strains are shown in Table 1. PRRSV strains were grown in porcine alveolar macrophages (PAM) obtained from high health pigs of a farm historically free from all major pig diseases including pseudorabies, classical swine fever, PRRS and influenza. For assessing purity of the viral production, PAM batches were tested by reverse transcription (RT)-PCR or PCR for PRRSV, hepatitis E virus, Torque tenovirus and porcine circovirus type 2 according to previously published protocols (Martin et al., 2007; Mateu et al., 2003; Quintana et al., 2002; Segalés et al., 2009). Viral batches were tested for all those pathogens as well. All viral isolates were used as PAM supernatants (passage $n=3$ ). Viral RNA was extracted from supernatants by using the QiaAMP viral RNA minikit (Qiagen, Barcelona, Spain) according to the manufacturer instructions. 
Reverse transcription was done using Superscript II Reverse transcriptase and random hexamers (Invitrogen, Barcelona, Spain). The obtained cDNA was then used in specific PCRs designed to amplify overlapping segments of the viral genome (Table 2). Both strands of PCR products were sequenced using the Genetic Analyzer 3130 XL (Applied Biosystems). When deletions in the genome were found, confirmation was carried out by re-sequencing of the products and synthesizing of new primers flanking the supposed deletion and further amplification and sequencing.

- Analysis of viral sequences. Sequences were examined and purged of errors using Chromas Pro 1 (Larkin et al., 2007). Predicted amino acid sequences were obtained by translation using BioEdit (Hall., 1999). Nucleotide sequences were aligned using Clustal X2 with correction for multiple substitutions. Bootstrap values were calculated after 1000 iterations using the Neighbor-joining method. For comparative purposes available full length sequences of genotype I (Genbank Accession numbers: M96262Lelystad virus; AY366525-North American EuroPRRSV; AY588319-LV-4.2.1; DQ864705-strain 01CB1 from Thailand; DQ489311-viral clone; EU076704-strain HKEU16 from Hong Kong; FJ349261- strain KNU07 from Korea and GQ461593strain SHE from China) and genotype II (Genbank accession numbers: AF066183, AF325691, AY032626, AY424271, AY545985, G EU880437, EU708726, Q857656, NC_001961, U87392) PRRSV sequences were also included. Synonymous (dS) and non-synonymous (dNS) substitutions in each ORF were calculated using SNAP (Körber., 2000) available at http://hcv.lanl.gov/content/sequence/SNAP/SNAP.html and expressed as dS-dNS values. Topological trees were built up with Mega4 (Tamura et al., 2007) and rooted on mid-points. Predicted amino acid sequences were also examined for variations in the linear B-epitopes reported by Oleksiewicz et al. (2000, 
2001), and in the neutralization epitopes (NE) known to be located in GP4 (Meulenberg et al., 1997) and GP5 (Plagemann., 2004).

\section{. Cytokine induction in peripheral blood $\mathrm{CD172a}^{+}$cells and PAM. Recent papers} indicated the role of non structural proteins in the regulation of the immune response to PRRSV through cytokine release. Since full ORF1a and 1b sequences were available, cytokine induction by the different PRRSV isolates was examined using peripheral blood CD172 $\mathrm{a}^{+}$cells or alveolar macrophages. PBMC and PAMs were obtained from healthy pigs of the same litters than above. CD172a ${ }^{+}$cells were purified from PBMC by positive selection using MACS Microbeads (Miltenyi Biotech SL, Spain). Briefly, cells were incubated with mouse anti porcine CD172a-FITC (Serotec, Spain) on ice for 30 minutes. After incubation, PBMC were washed and CD172 ${ }^{+}$cells were coupled (15 min on ice) with anti-FITC magnetic particles (Miltenyi Biotech SL, Spain). PBMC were washed again, re-suspended in MACS buffer (PBS plus foetal calf serum) and labeled cells were retrieved using LS selection columns (Miltenyi Biotec SL, Spain) according to manufacturer's instructions. Purity of the cellular suspension was examined by flow cytometry analysis before further characterization. The obtained cell suspension always had a richness of $\mathrm{CD} 172 \mathrm{a}^{+} \geq 92 \%$. PAM were obtained by bronchoalveolar lavage of lungs of piglets. Briefly, after humane euthanasia, lungs were removed aseptically and washed by infusion through the trachea of PBS (Sigma, Spain) supplemented with $2 \%$ gentamicin. The retrieved cell suspension was centrifuged (10 minutes at $450 \mathrm{~g}$ ), washed and cells were frozen at $-150^{\circ} \mathrm{C}$ until needed. PAM were produced by adhesion to plastic of the retrieved cells. Parallel cultures of PAM were always examined for absence of pathogens as described above. PAM and CD172a+ cells were seeded at a density of $5 \times 10^{5}$ cells/well in $0.5 \mathrm{ml}$ volume and stimulated with viable PRRSV (2982; 3249; 3256; 3262; 3266 and 3267 strains) at 0.01 m.o.i for $24 \mathrm{~h}$. 
144 All strains were examined three times (separate days), in triplicate cultures each time.

145 For a given series of tests, all strains were tested in cells coming from the same animals.

146 As a negative control, supernatants from mock-infected PAM were included. Each time,

147 cell culture supernatants of the three replicas were collected and mixed and the resulting

148 mixtures were examined by ELISA for determining concentrations of different

149 cytokines. Because of the greater sensitivity of CD172a+ for producing IFN- $\alpha$, IL-10

150 and TNF- $\alpha$ (Gimeno et al., in press), these cytokines were examined in cell culture

151 supernatants of CD172 $\mathrm{a}^{+}$cells while supernatants of PAM were used to examine IL-1,

152 IL-6 and IL-8. IFN- $\alpha$ capture ELISA was performed as reported previously (Guzylack-

153 Piriou et al., 2004) using K9 and F17 monoclonal antibodies (Grupo Taper SA, Madrid,

154 Spain). F17 was biotinylated (Phase Biotinylation Kit, PIERCE, Spain). IFN- $\alpha$

155 recombinated protein (PBL Biomedical lab, Piscataway, New Jersey) was used as a

156 standard. IL-10 capture ELISA was performed using commercial pairs of mAbs (swine

157 IL-10, Invitrogen, Barcelona, Spain) (Díaz et al., 2005). TNF- $\alpha$, IL-1, IL-6 and IL-8

158 capture ELISAs were performed using matched antibody pairs according to

159 manufacturer's instructions (R\&D systems, Spain). The cut-off point of each ELISA

160 was calculated as the mean optical density of negative controls plus three standard

161 deviations. Values for the cytokine concentration in cell culture supernatants were

162 calculated as a corrected concentration resulting of the subtraction of cytokine levels in

163 mock-stimulated cultures from the values obtained for virus-stimulated cultures

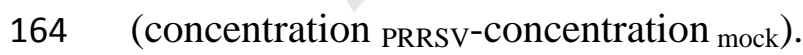

165 .Statistics. Statistical analysis was done using StatsDirect 2.7.5. $\chi^{2}$ test was used to 166 compare proportion of substitutions in the different viral proteins; comparison of results 167 obtained in VNT and ELISPOT was done using the Kruskal-Wallis test. 


\section{Results}

. Alignment and comparison of PRRSV genomic and predicted amino acid (aa) sequences. Global results for the comparison of ORFs and predicted proteins are shown in Table 3. Average similarity of the different ORFs among genotype I strains ranged from $94.7 \% \pm 2.4 \%$ for ORF7 to $89.5 \% \pm 4.4 \%$ for ORF1a. However this value for

ORF1a was strongly biased by the different values of similarity in each of the ORF1aencoded nsp. Thus, the higher variation was found in $\mathrm{nsp} 2$ which average similarity among examined genotype I strains (aa) was only of $83.3 \% \pm 6.7 \%$ followed by nsp $1 \alpha \beta$ with a $88.4 \% \pm 4.5 \%$. Interestingly, most of the variation in nsp1 accumulated in nsp $1 \beta$ where between aa positions 180 and 305 up to 66 substitutions were found (53\% of the positions). Figure 1 shows the aa alignment for nsp1. In nsp2, variation was even higher and concentrated between aa positions 269 and 430 with up to 88 positions with substitutions (55\%). However, the most relevant finding was the existence of deletions of different length. Strains 2982 and 3262 had a 74 aa deletion (positions 308-381), longer than any previously known nsp2 deletion in genotype I strains, for example AY366525, DQ489311 or FJ349261 (Figure 2). Strain 3256 had a 25 aa deletion distributed in two non-contiguous segments (346-358 and 418-429) and strain 3249 has a 1 aa deletion (aa 349). Porcilis PRRS also had a 74 aa deletion starting from position 281. When nsp2 protein sequences were compared among genotype I and II PRRSV strains it was found that the percentage of similarity was the lowest of all viral proteins (26.3\%). Similarities below $50 \%$ in the aa sequence were also found for nsp7 and nsp12. Average similarities for other proteins encoded by ORF1a or ORF1b were well above $90 \%$. 
192 Examination of the other ORFs and of the corresponding predicted proteins showed that

193 ORF3 and ORF4 were the next genes with a higher variability (89.9\% of average

194 similarity in both cases); however, the percentage of positions with amino acid

195 substitutions showed a trend for being higher in GP4 (57 out of 183 aa, 31\%) compared

196 to GP3 (63 out of 265 aa, 24\%; p=0.08). Figures 3 and 4 show the alignments for GP3

197 and GP4, respectively. For GP3 a two aa deletion was found in strain 3262 (positions

198 235-236) corresponding to the same region previously reported to be deleted for Hong

199 Kong strain EU076704. In GP4, a two aa deletion was also found in strain 3262

200 (positions 59-60) upstream of a known eight aa deletion in strain EU076704 (positions

201 57-64). Regarding GP5, it is worth noting that $30 \%$ of the aa positions could harbor a

202 substitution being the fourth viral protein after nsp2, nsp1 and GP4 in the proportion of

variable positions. The global analysis of dS-dNS substitutions showed that density of dNS mutations was higher in nsp1, nsp2, the carboxy-terminal segment of GP3, the whole GP4 and the amino-terminal part of GP5 (Figure 5).

. Phylogenetic grouping of PRRSV strains. Phylogenetic analysis of whole ORFs 1-7 is shown in figure 6. According to the bootstrapped phylogenetic tree, strains 2982 and 3262 formed a cluster; strain 3266 clustered with DQ864705; 3267 clustered with GQ461593 and strains 3249 and 3256 grouped together. When phylogenetic trees were calculated based on the particular ORF sequences of those same strains, it was observed that grouping of sequences varied depending on the ORF or even the segment used. For example, in ORF4 strain 2982 formed a significant cluster with strain GQ461593 and strain 3249 clustered with FJ349261 but did not in any other ORF, and 3249 clustered with 3267 in nsp5 (not shown). Globally, grouping obtained with ORF1b was the most similar to that obtained with the whole virus sequence. In contrast, grouping based on 
217 ORF5 or ORF7 produce very dissimilar trees when compared with the one obtained

with the almost whole viral sequence (igure 6). Since sequencing of whole ORF1b is not useful for practical purposes, trees based on individual nsp were examined. Of these, nsp9 results were the most similar to the whole virus examination (Figure 6).

- Variation in linear B-epitopes of PRRSV. Predicted amino acid sequences were examined for changes in B-epitopes reported before in the literature. Regarding the known linear epitopes described by Oleksiewicz et al. (2001) it is worth to note that out of nine serologically confirmed epitopes, seven (ES1, ES3, ES4, ES6, ES7, ES9, ES11) had substantial variations. Particularly, ES3 and ES4 were deleted in strains 2982 and 3262. Figures 1 and 2 show variations in the cluster of epitopes present in nsp1 and nsp2. Regarding the epitope reported by Oleksiewicz et al. (2000) in GP3 (which core was RKASLSTS), that epitope was absent in the examined sequences. Variations in the core of the NE in GP4 (aa 59-66 in Lelystad virus) were found in most of the sequences; deletions were even found in strains 3262 and EU076704 (Figure 4). In contrast, for the NE in GP5, variations were only found regarding the glycosylation site at N-37 and thus, strains 2982, 3256 and 3262 were predicted to have this third glycosylation site at N-37 (not shown).

- Cytokine induction by different strains. Table 4 shows the results of the cytokine ELISAs. All tested strains were unable to induce IFN- $\alpha$ or IL-6 release; in contrast, all of them induced very high levels of IL-8 and IL-1 and, particularly, strain 3256 induced the highest IL-1 levels. Regarding TNF- $\alpha$, only strains 2982, 3249, 3256 and, 3262 induced release of this cytokine, being 3262 the strongest inducer. Strains 2982, 3256 and 3262 induced secretion of IL-10, being the 3256 the one yielding the higher $\underline{\text { response. }}$ 


\section{Discussion}

242 A review of the literature about the genetic diversity and variations of genotype-I

243 PRRSV reveals that most of the papers deal with variations in ORF5/GP5 and ORF7/N

244 protein. The scarce remaining papers that examined the whole viral genome or almost

245 the whole viral genome (Amonsin et al., 2009; Fang et al., 2004; Nam et al., 2009;

246 Roop et al., 2004) were mostly focused in a particular strain or a very narrow set of

247 strains. Therefore, knowledge in that area is limited and often this has leaded to assume

248 that most facts described for a single genotype-I or genotype-II isolate could represent

249 all PRRSV strains.

251 The present study further confirms that diversity of genotype-I isolates of PRRSV is

252 high and, that variability within the viral genome is unequally distributed. Thus, ORF1a,

253 ORF3 and ORF4 account for the highest diversity $(10.5 \% ; 10.1 \%$ and $10.1 \%$, of

254 variation, respectively). The examination of the topological distribution of dS-dNS

255 offers a finer picture of this. Within ORF1a, most substitutions and deletions

256 accumulate in nsp1 and nsp2 while for other nsp in that ORF1a, similarities are over

$25795 \%$. Within nsp1, the highest variability is observed in nsp1 $\beta$. Recently, Beura et al.

258 (2010) showed the importance of nsp1 for inhibiting activation of the IFN- $\beta$ promoter

259 and that nsp1 $\beta$ inhibited NF- $\kappa \beta$ signalling. According to those authors, IL- 8 mRNA

260 induction upon dsRNA treatment (mediated by TLR-3) was reduced by nsp1 $\beta$

261 expression. In our study, in spite of the extremely high variability found in nsp1 $\beta$ (up to

26298 positions with substitutions out of 219 aa; 45\%) none of the six tested strains had the

263 ability to induce detectable levels of IFN- $\alpha$ and, contrarily to what could be expected

264 from the results of Beura et al. (2010), all strains were extremely able inducers of IL-8, 
266 Beura et al., that other parts of the virus may also be good IL-8 inducers, or that levels

267 of nsp1 $\beta$ necessary to produce such an inhibition of IL- 8 mRNA are attainable in nsp1 $\beta$

268 -transfected HEK-293 cells but not in infected PAM.

269 Nevertheless, the most variable part of the virus was nsp2. In the present study the 270 length of the predicted protein varied from 861 aa (i.e. Lelystad virus) to 787 aa in 271 strains 2982 and 3262. The 74 aa deletion in nsp2 of those two isolates is the largest 272 deletion known up to date in genotype-I strains (Nam et al., 2009; Roop et al., 2004) and confirm the non-essential nature of the segment comprised between residues 280 and 380 of genotype-I nsp2. Moreover, it is interesting to note that the most negative dS-dNS values were located in nsp2 and that similarity between genotype-I nsp2 and genotype-II nsp2 can be as low as $24 \%$. These facts evidence that evolutive pressures act with high intensity upon this protein and are compatible with an important role of this protein in the immune regulation. Chen et al. (2010) suggested recently that deletion of some epitopes in nsp2 may lead to substantial changes in the biological properties of a given PRRSV strain. According to those authors, deletion of epitope ES3 in nsp2 probably result in an enhanced in vitro an in vivo replicative ability as well as decreased ability to induce IL-1 $\beta$ and TNF- $\alpha$ responses in peripheral blood mononuclear cells or macrophages. In the case of the present study, strains 2982 and 3262 that had natural deletion of ES3 did not replicate better than strains harbouring a full nsp2 (i.e. 3266 or 3267) even they yielded lower titres. However, since parental undeleted- ancestor of strains 2982 or 3262 were unknown, it cannot be ascertained if the deletion had or not an essential effect on the replicative ability of PRRSV in macrophages but it is interesting to remark that the vaccine strain Porcilis PRRS, that is 
known for replicating poorly in macrophages, also harboured a 74 aa deletion in that segment of nsp2.

291 Regarding the cytokine induction by the examined strains, it is worth to remark that 292 strains with extensive 25 aa or 74 aa deletions in nsp2 were the only inducing 293 simultaneously IL-10 and TNF- $\alpha$ release. In the case of 3262 (with a 74 aa deletion 294 affecting ES3 and ES4), levels of TNF- $\alpha$ were the highest of the six examined strains. These results are in apparent contradiction with those reported by $\underline{\text { Chen et al. (2010) }}$ who observed that deletion in ES3 seemed to impaired TNF- $\alpha$ release. As seen in the

297 present paper, field strains are in fact diverse and may harbour different deletions and substantial variations in nsp2. Other authors have also reported that nsp1 suppresses tumor necrosis factor-alpha promoter activation (Subramaniam et al., 2010). In this scenario, the biological properties of a given strain will be the result of the combination of all those elements of variation and not only of a given one, and thus one may counteract the effect of another. This may well explain this apparent contradiction.

Besides this, when strains are phylogenetically examined, it can be observed that the same isolates can cluster differently when different viral proteins are looked upon. In our opinion, these results were highly suggestive of differential selective pressures in different genes, potential recombination or reassortment. At this point we are unable to clearly determine the cause. The functional role of the specific nsps, such as nsp $1 \alpha / \beta$, $\underline{\mathrm{nsp} 2, \mathrm{nsp} 4, \mathrm{nsp} 7 \text {, and nsp11, is the modulation of host immune responses to PRRSV }}$ infection and the nsp3-8 region has been identified as containing major virulence

310 factors (Fanga and Snijderb, 2010). In consequence, it is not uncommon observing the highest genetic diversity in those target viral regions suffering direct pressure of the host defence mechanisms. Interestingly, nsp9 seems to represent the whole virus better than 
any other else protein. As nsp9 encodes for a virus-encoded RNA-dependent RNA

polymerase and it is responsible of the replication of single-stranded RNA viruses with

genomes of positive polarity, this protein seems to be the most conserved among strains.

The abovementioned variability most probably will also affect antigenic properties of

the virus, such as the induction of NA by GP5 (Plagemann et al., 2002) and recently by

GP4 (Vanhee et al., 2010). When the predicted viral proteins were analyzed for the

variation in known linear B-epitopes, it could be seen that in the set of linear epitopes

reported by Oleksiewicz et al. (2001) only ES2 and ES5 were relatively conserved and

ES3 and ES4 can be non existent in field strains. This result suggests that the possibility

of constructing a marked differential vaccine by deleting some of the linear epitopes of the nsp2 cluster is at least, extremely difficult. On the other hand, we have made an approach considering linear B-epitopes but to have a full image relating antigenicity with sequence conservation, the tertiary protein structure also matters. It could be possible that tertiary structure-rich regions could interfere with the presentation of strictly linear epitopes to porcine B cells and predominate for instance in functional protein domains. Moreover, it is difficult to predict whether or not amino acid changes would correspond with changes in the recognition by monoclonal antibodies of these linear epitopes. Thus, prior to diagnostic exploitation, more information is needed about the biological significance of the abovementioned changes as well as about the interindividual variability in anti-ES responses.

In summary, taking together, the results of the present study reinforce the notion

334 (Stadejek et al., 2002, 2007, 2008) that genetic diversity in PRRSV is very high and shows that nsp1, nsp2 and ORFs 3 and 4 suffer the highest degree of variation within the viral genome. This variability also affects most of the known linear B-epitopes of

337 the virus and may have also an impact on the biological properties of the virus. Also, 
338 the present paper shows that different strains can have substantially different

339 immunobiological properties. These data can contribute to the understanding of the 340 complexity of PRRSV.

\section{Aknowledgements}

343 Our grateful thanks to Núria Navarro, Esmeralda Cano, Anna Coll and Montse Tello for

344 their assistance in the laboratory. We would also like Dr. María Montoya for her help in 345 obtaining CD172a ${ }^{+}$cells and Dr. Martí Cortey for his helpful assistance in the genetic 346 analysis. This project was supported by a grant from the Spanish Ministry for Science 347 and Innovation (MICINN) reference AGL2008-05708-C02-02/GAN. Ivan Diaz was 348 supported by the project CSD-007-Porcivir of the program Consolider Ingenio 2010. 


\section{References}

351

352

353

354

355

356

357

358

359

360

361

362

363

364

365

366

367

368

369

370

371

372

1. Amonsin A., Kedkovid R., Puranaveja S., Wongyanin P., Suradhat S., Thanawongnuwech R., 2009. Comparative analysis of complete nucleotide sequence of porcine reproductive and respiratory syndrome virus (PRRSV) isolates in Thailand (US and EU genotypes). Virol. J. 6,143.

2. Beura L.K., Sarkar S.N., Kwon B., Subramaniam S., Jones C., Pattnaik A.K., Osorio F.A., 2010. Porcine reproductive and respiratory syndrome virus non structural protein $1 \beta$ modulates host innate immune response by antagonizing IRF3 activation. J. Virol. 84,1574-84

3. Chen Z., Zhou X., Lunney J.K., Lawson S., Sun Z., Brown E., ChristopherHennings J., Knudsen D., Nelson E., Fang Y., 2010. Immunodominant epitopes in nsp2 of porcine reproductive and respiratory syndrome virus are dispensable for replication but play an important role in modulation of host immune response. J. Gen. Virol. 91, 1047-57.

4. Collins J.E., Benfield D.A., Christianson W.T., Harris L., Hennings J.C., Shaw D.P., Goyal S.M., McCullough S., Morrison R.B., Joo H.S., Gorcyca D., Chladek D., 1992. Isolation of swine infertility and respiratory syndrome virus (isolate ATCC VR-2332) in North America and experimental reproduction of the disease in gnotobiotic pigs. J. Vet. Diagn. Invest. 4: 117-126.

5. Díaz, I., Darwich L., Pappaterra G., Pujols J., Mateu E., 2005. Immune responses of pigs after experimental infection with a European strain of Porcine reproductive and respiratory syndrome virus. J. Gen. Virol. 86, 1943-1951.

6. Fang Y., Snijder EJ., 2010. The PRRSV replicase: exploring the multifunctionality of an intriguing set of nonstructural proteins. Virus Res. 154:61-76.

7. Fang Y., Kim D.Y., Ropp S., Steen P., Christopher-Hennings J., Nelson E.A., Rowland R.R., 2004. Heterogeneity in Nsp2 of European-like porcine 
reproductive and respiratory syndrome viruses isolated in the United States. Virus. Res. 100, 229-235.

8. Forsberg R., Oleksiewicz M.B., Petersen A.M., Hein J., Bøtner A., Storgaard T., 2001. A molecular clock dates the common ancestor of European-type porcine reproductive and respiratory syndrome virus at more than 10 years before the emergence of disease. Virology 289, 174-179.

13. Keffaber K.K., 1989. Reproductive failure of unknown etiology, Am. Assoc. Swine. Prac. Newsl. 1, 1-9.

10. Gimeno M., Darwich L., Diaz I., de la Torre E., Pujols J., Martin M., Inumaru S., Cano E., Domingo M., Montoya M., Mateu E., 2011. Cytokine profiles and phenotype regulation of antigen presenting cells by genotype-I porcine reproductive and respiratory syndrome virus isolates. Vet. Res., in press.

11. Guzylack-Piriou L., Balmelli C., McCullough K.C., Summerfield A., 2004. Type-A CpG oligonucleotides activate exclusively porcine natural interferonproducing cells to secrete interferon-alpha, tumour necrosis factor-alpha and interleukin-12. Immunology 112, 28-37.

12. Hall T.A., 1999. BioEdit: a user-friendly biological sequence alignment editor and analysis program for Windows 95/98/NT, Nucl. Acids. Symp. Ser. 41:9598.

14. Körber B., 2000. HIV Signature and Sequence Variation Analysis. Computational Analysis of HIV Molecular Sequences, Chapter 4, pages 55-72. Allen G. Rodrigo and Gerald H. Learn, eds. Dordrecht, Netherlands: Kluwer Academic Publishers. 
15. Larkin M.A., Blackshields G., Brown N.P., Chenna R., McGettigan P.A., McWilliam H., Valentin F., Wallace I.M., Wilm A., Lopez R., Thompson J.D., Gibson T.J., Higgins D.G., 2007. Clustal W and Clustal X version 2.0. Bioinformatics 23, 2947-2948.

16. Martín M., Segalés J., Huang F.F., Guenette D.K., Mateu E., de Deus N., Meng X.J., 2007. Association of hepatitis E virus (HEV) and postweaning multisystemic wasting syndrome (PMWS) with lesions of hepatitis in pigs. Vet. Microbiol. 122, 16-24.

19. Nam E., Park C.K., Kim S.H., Joo Y.S., Yeo S.G., Lee C., 2009. Complete genomic characterization of a European type 1 porcine reproductive and respiratory syndrome virus isolate in Korea. Arch. Virol. 154, 629-638.

20. Oleksiewicz M.B., Bøtner A., Toft P., Grubbe T., Nielsen J., Kamstrup S., Storgaard T., 2000. Emergence of porcine reproductive and respiratory syndrome virus deletion mutants: correlation with the porcine antibody response to a hypervariable site in the ORF 3 structural glycoprotein. Virology 267, 135140.

21. Oleksiewicz M.B., Bøtner A., Toft P., Normann P., Storgaard T., 2001. Epitope mapping porcine reproductive and respiratory syndrome virus by phage display: the nsp2 fragment of the replicase polyprotein contains a cluster of B-cell epitopes. J. Virol. 75, 3277-3290. 
22. Paton D.J., Brown I.H., Edwards S., Wensvoort G., 1991. Blue ear disease of pigs. Vet. Rec. 128, 617.

454

23. Plagemann P.G., Rowland R.R., and Gaaberg K.S., 2002. The primary neutralization epitope of porcine respiratory and reproductive syndrome virus strain VR-2332 is located in the middle of the GP5 ectodomain.Arch Virol. 147:2327-2347.

24. Plagemann P.G., 2004 GP5 ectodomain epitope of porcine reproductive and 461 respiratory syndrome virus, strain Lelystad virus. Virus. Res. 15, 225-230.

25. Quintana J., Balasch M., Segalés J., Calsamiglia M., Rodríguez-Arrioja G.M., Plana-Durán J., Domingo M., 2002. Experimental inoculation of porcine circoviruses type 1 (PCV1) and type 2 (PCV2) in rabbits and mice. Vet. Res. 33, 229-237.

28. Snijder E.J., Meulenberg J.J., 1998. The molecular biology of arteriviruses. J.

26. Ropp S.L., Wees C.E., Fang Y., Nelson E.A., Rossow K.D., Bien M., Arndt B., Preszler S., Steen P., Christopher-Hennings J., Collins J.E., Benfield D.A., Faaberg KS., 2004. Characterization of emerging European-like porcine reproductive and respiratory syndrome virus isolates in the United States. J. Virol. 78, 3684-3703.

27. Segalés J., Martínez-Guinó L., Cortey M., Navarro N., Huerta E., Sibila M., Pujols J., Kekarainen T., 2009. Retrospective study on swine Torque teno virus genogroups 1 and 2 infection from 1985 to 2005 in Spain. Vet. Microbiol. 134, 199-207.

$$
\text { Gen. Virol. 79, 961-979. }
$$

29. Stadejek T., Stankevicius A., Storgaard T., Oleksiewicz M.B., Belák S., Drew T.W., Pejsak Z., 2002. Identification of radically different variants of porcine reproductive and respiratory syndrome virus in Eastern Europe: towards a 
common ancestor for European and American viruses. J. Gen. Virol. 83, 18611873.

487

30. Stadejek T., Oleksiewicz M.B., Potapchuk D., Podgórska K., 2006. Porcine reproductive and respiratory syndrome virus strains of exceptional diversity in eastern Europe support the definition of new genetic subtypes. J. Gen. Virol. 87, 1835-1841.

31. Stadejek T., Oleksiewicz M.B., Scherbakov A.V., Timina A.M., Krabbe J.S., Chabros K., Potapchuk D., 2008. Definition of subtypes in the European genotype of porcine reproductive and respiratory syndrome virus: nucleocapsid characteristics and geographical distribution in Europe. Arch. Virol. 153, 14791488.

503

32. Subramaniam S., Kwon B., Beura L.K., Kuszynski C.A., Pattnaik A.K., Osorio F.A., 2010. Porcine reproductibe and respiratory syndrome virus non-structural protein 1 suppresses tumor necrosis factor-alpha promoter activation by

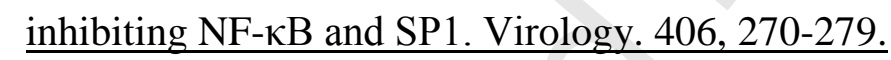

33. Tamura K., Dudley J., Nei M., Kumar S., 2007. MEGA4: Molecular Evolutionary Genetics Analysis (MEGA) software version 4.0. Molecular Biology and Evolution 24, 1596-1599.

34. Vanhee M., Costers S., Van Breedam W., Geldhof M.F., Van Doorsselaere J., Nauwynck H.J., 2010. A variable region in GP4 of European-type porcine reproductive and respiratory syndrome virus induces neutralizing antibodies against homologous but not heterologous virus strains. Viral Immunol. 23:40313.

35. Wensvoort G., Terpstra C., Pol J.M., ter Laak E.A., Bloemraad M., de Kluyver E.P., Kragten C., van Buiten L., den Besten A., Wagenaar F., et al., 1991. Mystery swine disease in The Netherlands: the isolation of Lelystad virus. Vet. Q. 13, 121-130. 
Table 1. Characteristics of PRRSV strains used in the present study.

\begin{tabular}{|c|c|c|c|c|c|}
\hline $\begin{array}{l}\text { Strain } \\
\text { reference }\end{array}$ & Country & $\begin{array}{l}\text { Year of } \\
\text { isolation }\end{array}$ & $\begin{array}{l}\text { Clinical signs } \\
\text { (field) }\end{array}$ & Tissue & $\begin{array}{l}\text { Maximum titer in } \\
\left.\text { PAM* }^{*} \mathrm{TCID}_{50} / \mathrm{ml}\right)\end{array}$ \\
\hline 2982 & Spain & 2005 & $\begin{array}{l}\text { Respiratory } \\
\text { (weaners) }\end{array}$ & $\begin{array}{c}\text { Lung } \\
\text { (weaner) }\end{array}$ & $10^{4.7}$ \\
\hline 3249 & Spain & 1992 & Abortions & $\begin{array}{l}\text { Serum } \\
\text { (sow) }\end{array}$ & $10^{4.7}$ \\
\hline 3256 & Spain & 2005 & $\begin{array}{l}\text { Respiratory } \\
\text { (weaners) }\end{array}$ & $\begin{array}{c}\text { Lung } \\
\text { (weaner) }\end{array}$ & $10^{4}$ \\
\hline 3262 & Spain & 2005 & $\begin{array}{l}\text { Respiratory } \\
\text { (weaners) }\end{array}$ & $\begin{array}{c}\text { Lung } \\
\text { (weaner) }\end{array}$ & 5.9 \\
\hline 3266 & Germany & 1992 & Abortions & $\begin{array}{l}\text { Serum } \\
\text { (sow) }\end{array}$ & \\
\hline 3267 & Portugal & 2006 & $\begin{array}{l}\text { None } \\
\text { (boar) }\end{array}$ & $\begin{array}{l}\text { Serum } \\
\text { (boar) }\end{array}$ & $10^{7.3}$ \\
\hline
\end{tabular}

*PAM $=$ Porcine alveolar macrophages

$\mathrm{TCID}_{50}=$ Tissue culture infectious dose $50 \%$ 
Table 2. List of oligonucleotide primers utilized for amplifying the ORFs of PRRSV strains.

\begin{tabular}{|c|c|c|c|c|}
\hline Fragment & Primer pair & Primer sequence $^{\mathrm{a}}$ (5'to 3' sense) & $\begin{array}{c}\text { Annealing } \\
\mathrm{T}^{\mathrm{a}}\left({ }^{\circ} \mathrm{C}\right)\end{array}$ & $\begin{array}{c}\text { Primer } \\
\text { location }\end{array}$ \\
\hline \multirow[t]{65}{*}{ ORF 1} & $1.0 \mathrm{~F}$ & CCTGTTCTAGCCCAACAGGT & 55 & 93 \\
\hline & $1.0 \mathrm{R}$ & AGCCGCGCTCGTAAACT & 55 & \\
\hline & $1.1 \mathrm{~F}$ & TGCTGATGTTTTGTACCGTGA & 55 & 524 \\
\hline & $1.1 \mathrm{R}$ & CAGCACTTGCCATCAAACAC & 55 & \\
\hline & $1.1 \mathrm{~B}-\mathrm{F}^{\mathrm{c}}$ & TTCCTCCAACGACTTGTGARGGTTGC & 55 & 501 \\
\hline & $1.1 \mathrm{~B}-\mathrm{R}^{\mathrm{c}}$ & CCATGCACGCCCCACTTGGTTTG & 55 & \\
\hline & $1.2 \mathrm{~F}$ & GTGTTTGATGGCAAGTGCTG & 55 & 1032 \\
\hline & $1.2 \mathrm{R}$ & ATTATGGCGGCAAGGACAT & 55 & \\
\hline & $1.3 \mathrm{~F}$ & GACAGACGGGTCTTGTGGTT & 55 & 1493 \\
\hline & $1.3 \mathrm{R}$ & CATTTTTGCGGAACAACCTC & 55 & \\
\hline & $1.4 \mathrm{~F}$ & GAGGTTGTTCCGCAAAAATG & 55 & 2007 \\
\hline & $1.4 \mathrm{R}$ & CTGGTTGGGACAAATCCAGT & 55 & \\
\hline & $1.4 \mathrm{~B}-\mathrm{F}^{\mathrm{d}, \mathrm{e}}$ & TGTCCGAGYTCYAAACAGGCCATG & 51 & 2079 \\
\hline & $1.4 \mathrm{~B}-\mathrm{R}^{\mathrm{d}, \mathrm{e}}$ & CGGCATCAGAACCTGGGTTGT & 51 & \\
\hline & $1.5 \mathrm{~F}$ & ACGAACCACTGGATTTGTCC & 55 & 2518 \\
\hline & $1.5 \mathrm{R}$ & GAGTTCGGCAAATTCGAAAG & 55 & \\
\hline & $1.6 \mathrm{~F}$ & TTCTCCGCACAAGCCTTAAT & 55 & 3021 \\
\hline & $1.6 \mathrm{R}$ & CTGATAGACCCCGCGAGAC & 55 & \\
\hline & $1.6 \mathrm{~B}-\mathrm{F}^{\mathrm{d}, \mathrm{e}}$ & CCTGGACCAGCCTTTAGATCT & 50 & 2729 \\
\hline & $1.6 \mathrm{~B}-\mathrm{R}^{\mathrm{d}, \mathrm{e}}$ & CTGGGAGATGGGAGACAATTTC & 50 & \\
\hline & $1.7 \mathrm{~F}$ & GGGCGGGAGTTGGAAA & 55 & 3488 \\
\hline & $1.7 \mathrm{R}$ & CGTGACCCACCGAGTAACTT & 55 & \\
\hline & $1.8 \mathrm{~F}$ & CGGTGGGTCACGTTATCTCT & 55 & 3951 \\
\hline & $1.8 \mathrm{R}$ & AGCCACAAAAGTGTCCGAAT & 55 & \\
\hline & $1.9 \mathrm{~F}$ & TGGACCAGCCTACACCTGA & 55 & 4378 \\
\hline & $1.9 \mathrm{R}$ & TGGGTCAGCGGTTCCTC & 55 & \\
\hline & $1.10 \mathrm{~F}$ & GACCCATGGTGTTCAAATCC & 55 & 4716 \\
\hline & $1.10 \mathrm{R}$ & TGTAATAATTCCGGCAACCTG & 55 & \\
\hline & $1.11 \mathrm{~F}$ & TCTCAGCCGTGGCACA & 55 & 4819 \\
\hline & $1.11 \mathrm{R}$ & CGGTGTTAAGGCAGGGTTT & 55 & \\
\hline & $1.12 \mathrm{~F}$ & CCTGCCTTAACACCGTGAAT & 55 & 5323 \\
\hline & $1.12 \mathrm{R}$ & CCAAGTCACTCGGAATGGAT & 55 & \\
\hline & $1.13 \mathrm{~F}$ & CCTAGCCTCCGTCCCTGTA & 55 & 5885 \\
\hline & $1.13 \mathrm{R}$ & TAGGAAGAAGGCGCTTGAAA & 55 & \\
\hline & $1.13 \mathrm{~B}-\mathrm{F}^{\mathrm{d}}$ & CGAGCGTTCCCCTTGGAGACAT & 55 & 5883 \\
\hline & $1.13 \mathrm{~B}-\mathrm{R}^{\mathrm{d}}$ & CAGCCGTTAGGGACTCGTTACTCA & 55 & \\
\hline & $1.14 \mathrm{~F}$ & TTTCAAGCGCCTTCTTCCTA & 55 & 6385 \\
\hline & $1.14 \mathrm{R}$ & GCGGACCATTCTCAAAAAGA & 55 & \\
\hline & $1.14 \mathrm{~B}-\mathrm{F}^{\mathrm{c}, \mathrm{f}}$ & GTGGCTATTCAAATACCGGTGC & 45 & 6332 \\
\hline & $1.14 \mathrm{~B}-\mathrm{R}^{\mathrm{c}, \mathrm{f}}$ & TTCATCCTCTCAACTTTGAGATC & 45 & \\
\hline & $1.15 \mathrm{~F}$ & ССССТСТTTTTGAGAATGGT & 55 & 6901 \\
\hline & $1.15 \mathrm{R}$ & AAAGCCTGTTCAGTGGTCAA & 55 & \\
\hline & $1.16 \mathrm{~F}$ & TTGACCACTGAACAGGCTTT & 55 & 7383 \\
\hline & $1.16 \mathrm{R}$ & GATTGCGGACTTGGTGTCTT & 55 & \\
\hline & $1.17 \mathrm{~F}$ & CAAGACACCAAGTCCGCAAT & 55 & 7916 \\
\hline & $1.17 \mathrm{R}$ & GGTTTTGGGCTTGGAACAGT & 55 & \\
\hline & $1.17 \mathrm{~B}-\mathrm{F}^{\mathrm{c}}$ & TGTTAGGGGGGATCCTGAGC & 52 & 7840 \\
\hline & $1.17 \mathrm{~B}-\mathrm{R}^{\mathrm{c}}$ & CCAAGCСТTCTTCATGAATGCCTG & 52 & \\
\hline & $1.18 \mathrm{~F}$ & GTTCCAAGCCCAAAACCAG & 55 & 8400 \\
\hline & $1.18 \mathrm{R}$ & CTCGACCCACCAGTGGTAAT & 55 & \\
\hline & $1.19 \mathrm{~F}$ & ATTACCACTGGTGGGTCGAG & 55 & 8964 \\
\hline & $1.19 \mathrm{R}$ & GGTGACTGACACTGCGAACA & 55 & \\
\hline & $1.20 \mathrm{~F}$ & CGCAGTGTCAGTCACCTGTT & 55 & 9480 \\
\hline & $1.20 \mathrm{R}$ & CACACAAGGGGTGTTTTGG & 55 & \\
\hline & $1.21 \mathrm{~F}$ & CCAAAACACCCCTTGTGTGT & 55 & 10047 \\
\hline & $1.21 \mathrm{R}$ & CGAAATCGAGATGGACCTGT & 55 & \\
\hline & $1.21 \mathrm{~B}-\mathrm{F}^{\mathrm{e}}$ & GTGTCGTACCTCGATGAGGC & 55 & 9989 \\
\hline & $1.21 \mathrm{~B}-\mathrm{R}^{\mathrm{e}}$ & GCCCGAGTGATGGCTACAAG & 55 & \\
\hline & $1.21-22 \mathrm{~F}$ & CTTGTAGCCATCACTCGGGC & 50 & 10400 \\
\hline & $1.21-22 \mathrm{R}$ & CCCAGATTATGTGCCACTTGCG & 50 & \\
\hline & $1.22 \mathrm{~F}$ & CTCTCTTAGCCGCTTGTTCG & 55 & 10623 \\
\hline & $1.22 \mathrm{R}$ & GAGTCCTTAGGCAGGGACCTA & 55 & \\
\hline & $1.23 \mathrm{~F}$ & CCTACCTAGGTCCCTGCCTAA & 55 & 11107 \\
\hline & $1.23 \mathrm{R}$ & GATTGCCCAATCCTCAGTGT & 55 & \\
\hline & $1.24 \mathrm{~F}$ & CAATCCTTGCACGCCGTAT & 55 & 11604 \\
\hline
\end{tabular}




$\begin{array}{ll}\text { ORF2 } & 2 \mathrm{~F}^{\mathrm{g}} \\ & 2 \mathrm{R}^{\mathrm{g}} \\ & 2-3 \mathrm{~F} \\ & 2-3 \mathrm{R}\end{array}$

CTGGCACAGAATTGCAGGTA

ORF3 $\quad 3 \mathrm{~F}^{\mathrm{g}}$

ACAATGGCTCATCAGTGTGC

ORF4 $\quad 4 \mathrm{~F}^{\mathrm{g}}$

AGCGTGACCATGATGAGTTG

${ }^{a}$ Primers were initially designed based on sequence information available for LV (genBank accession number M96262); ${ }^{\mathrm{b}}$ Numbers correspond to position within the LV genome; $\mathrm{T}^{\mathrm{a}}$, temperature; $\mathrm{L}$, left or forward primer; $\mathrm{R}$, right or reverse primer; ${ }^{\mathrm{c}}$ primers used for amplifying 3256 strain; ${ }^{\mathrm{d}}$ primers used for 3262 strain; ${ }^{\mathrm{e}}$ primers used for 2982 strain; ${ }^{\mathrm{f}}$ primers used for 3249 strain ${ }^{\mathrm{g}}$ Díaz et al. 2006 (Virology 351: 249-259). 
Table 3. Similarity of the examined ORFs and of the predicted amino acid products of the 6 field strains and 9 European type PRRSV from the GenBank.

\begin{tabular}{|c|c|c|c|c|c|c|}
\hline ORF/Protein & Length (aa) & $\begin{array}{c}\text { Similarity gen. I* } \\
\text { (mean } \pm \text { sd) }\end{array}$ & Range & $\begin{array}{c}\text { Substitutions } \\
\text { (no aa; percentage } \text { ) }\end{array}$ & $\begin{array}{l}\text { Similarity gen. II** } \\
\text { (mean } \pm \mathrm{sd})\end{array}$ & Range \\
\hline ORF1a & $N A$ & $89.5 \% \pm 4.4 \%$ & $99.8-82.3 \%$ & $N D$ & $52.2 \% \pm 0.4 \%$ & $52.9-51.3 \%$ \\
\hline Nsp1 & 385 aа & $88.4 \% \pm 4.5 \%$ & $100-82.0 \%$ & $132 ; 34.3 \%$ & $52.2 \% \pm 0.9 \%$ & $54.3-50.5 \%$ \\
\hline Nsp2 & $861,844,841,836,787$ & $83.3 \% \pm 6.7 \%$ & $99.7-70.6 \%$ & $414 ; \geq 48.1 \%$ & $26.3 \% \pm 0.8 \%$ & $28.0-24.4 \%$ \\
\hline Nsp3 & 447 & $95.2 \% \pm 2.2 \%$ & $100-89.5 \%$ & $77 ; 17.2 \%$ & $56.7 \% \pm 0.6 \%$ & $58.0-55.3 \%$ \\
\hline Nsp4 & 203 & $95.0 \% \pm 4.3 \%$ & $100-90.1 \%$ & $39 ; 19.2 \%$ & $60.5 \% \pm 0.8 \%$ & $62.2-58.8 \%$ \\
\hline Nsp5 & 170 & $95.5 \% \pm 2.3 \%$ & $100-91.1 \%$ & $28 ; 16.4 \%$ & $71.0 \% \pm 1.7 \%$ & $73.5-66.4 \%$ \\
\hline Nsp6 & 16 & $95.3 \% \pm 4.4 \%$ & $100-81.2 \%$ & $3 ; 18.8 \%$ & $78.3 \% \pm 3.1 \%$ & $81.2-75.0 \%$ \\
\hline Nsp7 & 270 & $96.3 \% \pm 1.5 \%$ & $100-92.9 \%$ & $39 ; 14.4 \%$ & $44.6 \% \pm 0.8 \%$ & $46.5-43.2 \%$ \\
\hline Nsp8 & 44 & $97.5 \% \pm 2.5 \%$ & $100-90.9 \%$ & $5 ; 11.4 \%$ & $67.1 \% \pm 2.0 \%$ & $70.4-61.3 \%$ \\
\hline ORF1b & $N A$ & $93.2 \% \pm 3.1 \%$ & $99.8-87.3 \%$ & $N D$ & $62.7 \% \pm 0.3 \%$ & $63.3-62.0 \%$ \\
\hline Nsp9 & 645 & $97.9 \% \pm 1.0 \%$ & $100-96.1 \%$ & $48 ; 7.4 \%$ & $74.0 \% \pm 0.4 \%$ & $75.0-73.2 \%$ \\
\hline Nsp10 & 442 & $96.0 \% \pm 2.2 \%$ & $100-90.4 \%$ & $77 ; 17.4 \%$ & $63.4 \% \pm 0.5 \%$ & $64.7-62.2 \%$ \\
\hline Nsp11 & 224 & $97.4 \% \pm 1.2 \%$ & $100-94.6 \%$ & $26 ; 11.6 \%$ & $74.7 \% \pm 1.0 \%$ & $77.4-72.1 \%$ \\
\hline Nsp12 & 152 & $95.0 \% \pm 2.9 \%$ & $100-88.1 \%$ & $26 ; 17.1 \%$ & $39.3 \% \pm 0.6 \%$ & $40.7-38.2 \%$ \\
\hline ORF2a & $N A$ & $93.2 \% \pm 3.0 \%$ & 99.4-86.9\% & $N D$ & $63.8 \% \pm 0.7 \%$ & $66.9-62.6 \%$ \\
\hline GP2a & 249 & $93.3 \% \pm 3.0 \%$ & $98.7-87.5 \%$ & $61 ; 24.4 \%$ & $60.9 \% \pm 1.1 \%$ & $65.2-57.8 \%$ \\
\hline $\mathrm{P} 2 \mathrm{~b}$ & 70 & $96.4 \% \pm 3.3 \%$ & $100-88.5 \%$ & $9 ; 12.8 \%$ & $69.5 \% \pm 2.0 \%$ & $75.3-64.3 \%$ \\
\hline ORF3 & $N A$ & $89.9 \% \pm 5.2 \%$ & $100-80.5 \%$ & $N D$ & $62.1 \% \pm 0.7 \%$ & $63.7-60.6 \%$ \\
\hline GP3 & $265,263,257$ & $87.5 \% \pm 6.3 \%$ & $100-77.3 \%$ & $63 ; \geq 23.7 \%$ & $54.9 \% \pm 1.2 \%$ & $57.3-54.2 \%$ \\
\hline ORF4 & $N A$ & $89.9 \% \pm 5.0 \%$ & $100-80.9 \%$ & $N D$ & $64.5 \% \pm 1.2 \%$ & $66.8-77.0 \%$ \\
\hline GP4 & $183,181,175$ & $88.5 \% \pm 5.7 \%$ & $100-77.0 \%$ & $57 ; \geq 31.1 \%$ & $66.8 \% \pm 2.3 \%$ & $70.4-59.5 \%$ \\
\hline ORF5 & $N A$ & $91.1 \% \pm 3.7 \%$ & $99.8-84.0 \%$ & $N D$ & $60.7 \% \pm 0.7 \%$ & $62.4-58.5 \%$ \\
\hline GP5 & 202 & $90.0 \% \pm 3.5 \%$ & $99.5-84.0 \%$ & $62 ; 30.7 \%$ & $54.7 \% \pm 1.3 \%$ & $56.5-50.7 \%$ \\
\hline ORF6 & $N A$ & $93.8 \% \pm 3.3 \%$ & $100-88.1 \%$ & $N D$ & $69.2 \% \pm 0.7 \%$ & $69.2-71.2 \%$ \\
\hline $\mathrm{M}$ & 173 & $94.6 \% \pm 2.8 \%$ & $100-89.0 \%$ & $32 ; 18.5 \%$ & $78.8 \% \pm 1.2 \%$ & $81.6-75.2 \%$ \\
\hline ORF7 & $N A$ & $94.7 \% \pm 2.4 \%$ & $100-89.4 \%$ & $N D$ & $61.7 \% \pm 0.7 \%$ & $63.0-60.0 \%$ \\
\hline $\mathrm{N}$ & 127 & $95.0 \% \pm 3.3 \%$ & $100-88.2 \%$ & $24 ; 18.9 \%$ & $58.6 \% \pm 1.1 \%$ & $61.0-55.7 \%$ \\
\hline
\end{tabular}

* Similarity gen. I: Similarity among genotype I strains; ** Similarity gen. II: Similarity of genotype I with genotype II strains; ๆ Percentage was calculated over the longest aa length. NA; not applicable. ND; not done. 
Table 4. Cytokine levels in cultures of peripheral blood CD172a+ cells (IFN- $\alpha$, TNF- $\alpha$ and IL-10) or porcine alveolar macrophages (PAM) (IL-1, IL-6 and IL-8) stimulated with different viable PRRSV isolates at 0.01 multiplicity of infection as determined by capture ELISA. Values are shown in $\mathrm{pg} / \mathrm{ml}$.

\begin{tabular}{lcccccc}
\hline \multicolumn{7}{l}{ Cytokine levels in cell culture supernatants (pg/mI) } \\
\hline Strain & IFN- $\boldsymbol{\alpha}$ & TNF- $\boldsymbol{\alpha}$ & IL-1 & IL-8 & IL-6 & IL-10 \\
\hline $\mathbf{2 9 8 2}$ & Neg. & 376 & 304 & $>8000$ & Neg. & 212 \\
$\mathbf{3 2 4 9}$ & Neg. & 103 & 216 & $>8000$ & Neg. & Neg. \\
$\mathbf{3 2 5 6}$ & Neg. & 437 & 1232 & $>8000$ & Neg. & 723 \\
$\mathbf{3 2 6 2}$ & Neg. & 1119 & 411 & $>8000$ & Neg. & 461 \\
$\mathbf{3 2 6 6}$ & Neg. & Neg. & 301 & $>8000$ & Neg. & Neg. \\
$\mathbf{3 2 6 7}$ & Neg. & Neg. & 302 & $>8000$ & Neg. & Neg. \\
\hline Mock cells* & Neg. & Neg. & Neg. & $<1000$ & Neg. & Neg. \\
\end{tabular}

*Medium-stimulated cells. 
Figure 1. Graphic view of the alignment of the predicted amino acid sequences of non structural protein $1(1 \alpha$ and $1 \beta)$ for the examined PRRSV strains. Shadowed upper box shows nsp1 $\alpha$. Linear B-epitopes described by Oleksiewicz et al. (2001) are shown as dotted boxes with the label ESx.

M96262

2982

3249

3256

3262

3266

3267

Porcilis

AY588319

AY366525

EU076704

FJ349261

D0864705

DQ489311

GQ461593

M96262

2982

3249

3256

3262

3266

3267

Porcilis

AY588319

AY366525

EU076704

FJ349261

DQ864705

DQ489311

GQ461593

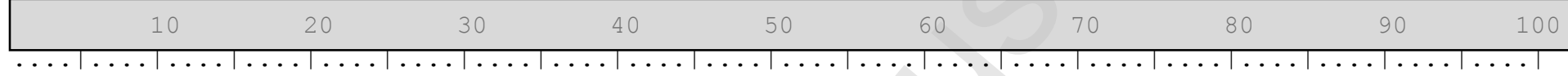

MSGTFSRCMCTPAARVFWNAGQVFCTRCLSARSLLSPELQDTDLGAVGLFYKPRDKLHWKVPIGI PQVECTPSGCCWLSAVFPLARMTSGNHNFLQRLVK

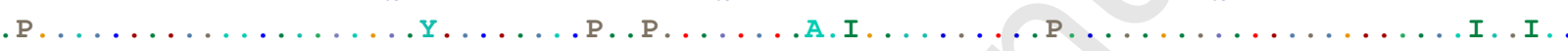

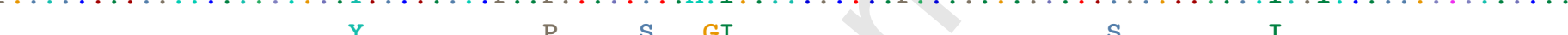

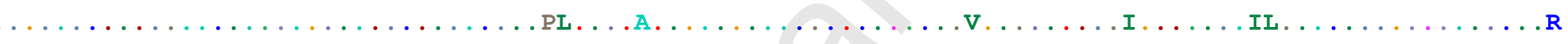

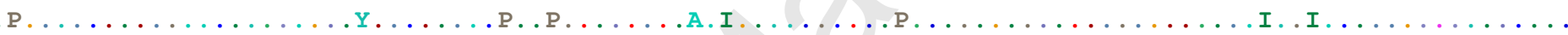

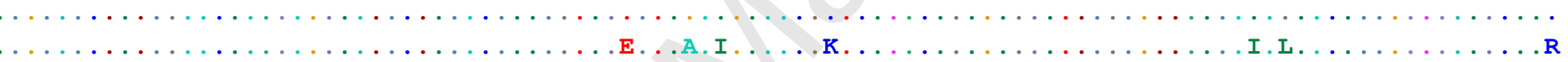

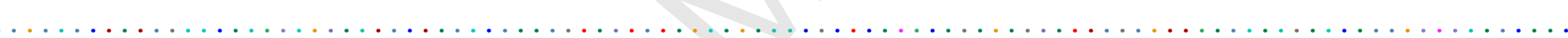

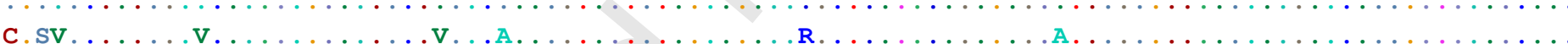

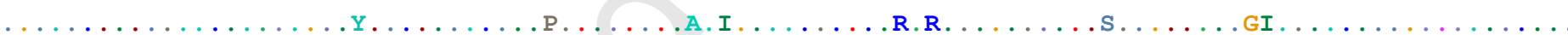

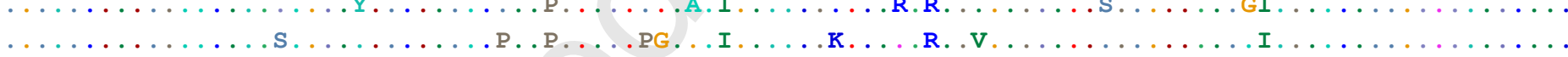

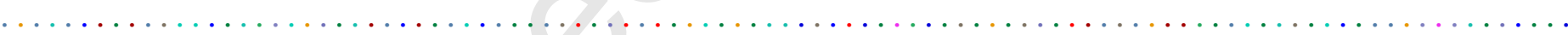

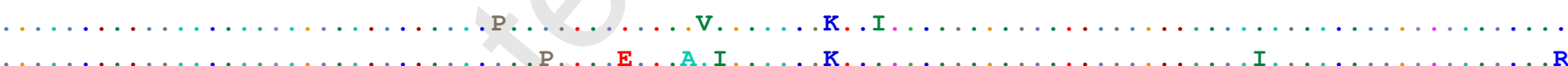

\begin{tabular}{|c|c|c|c|c|c|}
\hline 110 & 120 & 130 & 140 & 150 & 160 \\
\hline
\end{tabular}

VADVLYRDGCLAPRHLRELQVYERGCNWYPITGPVPGMGLFANSMHVSDQPFPGATHVLTNS PLPOQACROPFCPFEEAHSSVYRWKKFVVFTDSSLNGR

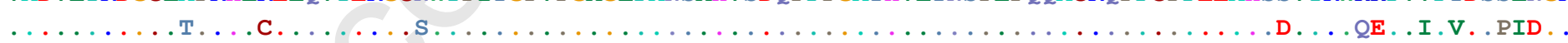

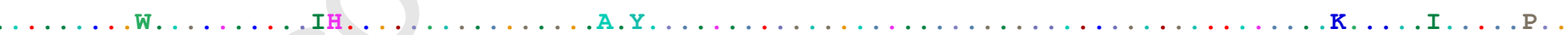


M96262

2982

3249

3256

3262

3266

3267

Porcilis

AY588319

AY366525

EU076704

FJ349261

DQ864705

DQ489311

GQ461593

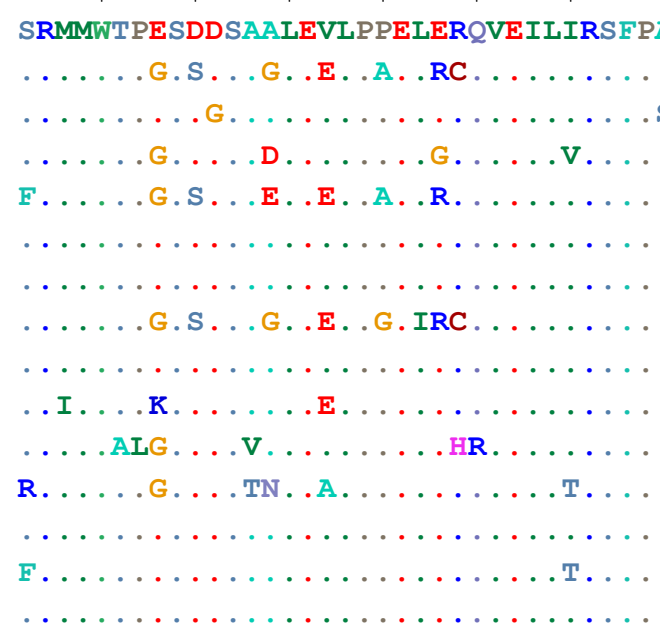

310

320

330

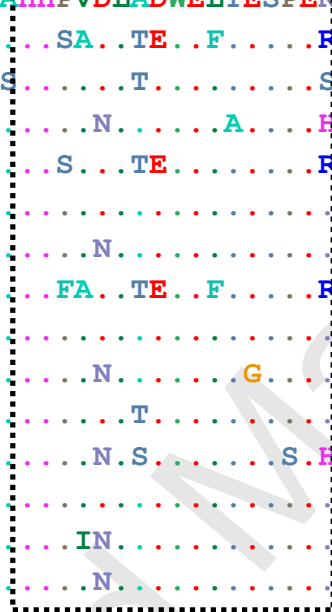

$340 \quad 350$
FSFNTSHSCGHLVONPDVFDGKCWLSCFLGOSVEVRCHEEHLADAFG



. . . . . . . . . . . . . . . . . . . . . HRC . . .

S Y.A.DH I

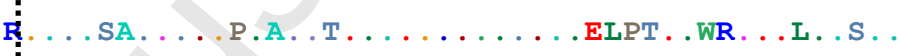

........E. E.

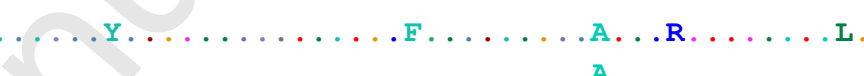

R.SN . . . . T. . . . . . . . . . . .

. . . . . . .

S....Y.A. . . S . .Y.L.TR.WR ..Y...

.S.F...Y.A...G.N......FDL.T. .WR ..Y..TL

G............................

360

370

380

$\ldots|\ldots| \ldots|\ldots| \ldots|\ldots| \ldots|\ldots| \ldots|\ldots| \ldots|\ldots| \ldots|\ldots| \ldots|\ldots| \ldots|\ldots| \ldots|\ldots|$

M96262

YQTKWGVHGKYLQRRLQVRGIRAVVDPDGPIHVEALSCPQSWIRHLTLDDDVTPGFVRLTSLRIVPNTEPTTSRIFRFGAHKWYG

2982

3249

3256

3262

3266

3267

Porcilis

AY588319

AY366525

EU076704

FJ349261

DQ864705

DQ489311

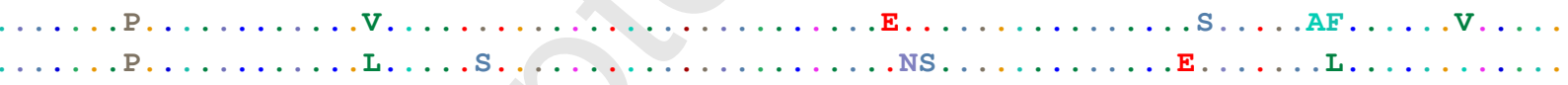

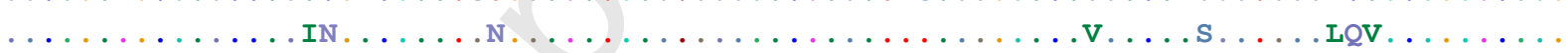

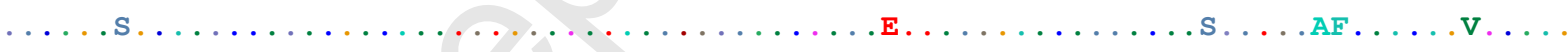

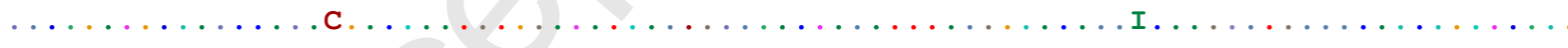

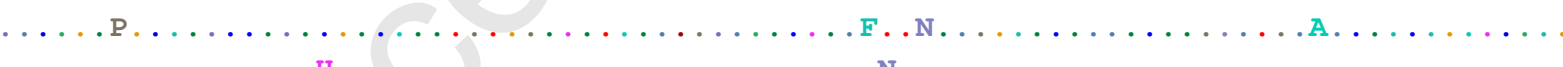

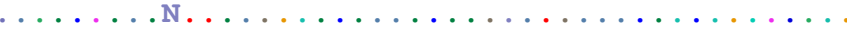

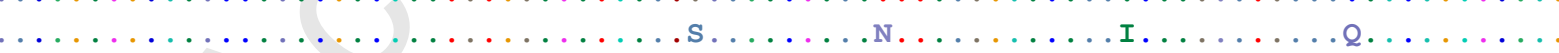

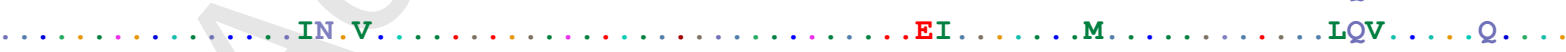

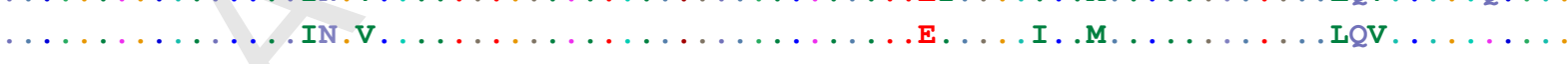

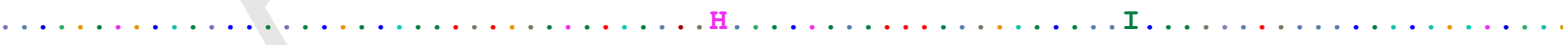

GQ461593

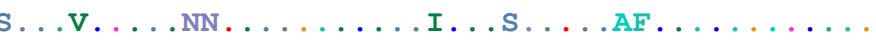

R.......... .

A. 
Figure 2. Graphic view of the alignment of the predicted amino acid sequences of non structural protein 2 for the examined PRRSv strains. Linear B-epitopes described by Oleksiewicz et al. (2001) are shown as dotted boxes with the label ESx.

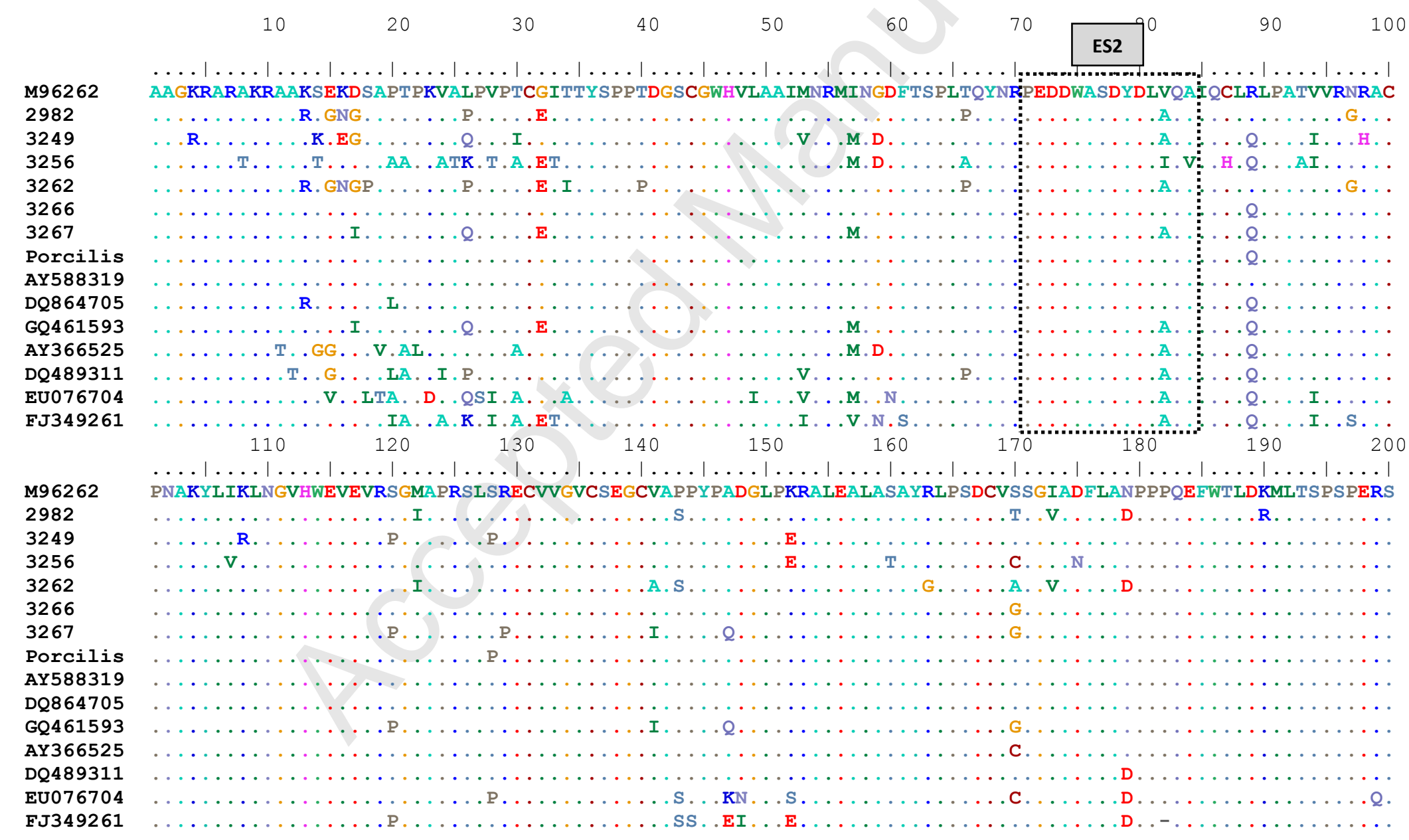


\begin{tabular}{lllllllll}
210 & 220 & 230 & 240 & 250 & 260 & 270 & 280 & 290 \\
\hline
\end{tabular} GFSSLYKLLLEVVPOKCGATEGAFIYAVERMLKDCPSSKOAMALIAKIKVPSSKAPSVSLDECFPTDVLADFEPASOERPQSSGAAVVLCSPDAKEFEEA $\ldots$
$\cdots$
$\cdots$ 310 ES3 $330 \quad 340$ 350 360 370 380 ES4 390

M96262

2982

3249

3256

3262

3266

3267

Porcilis

AY588319

DQ864705

GQ461593

AY366525

AY366525

2076704

FJ349261

APEEVQRSGHKAVHSALLAEGPNNEQVQVVAGEOLKL GC GLAVGNAHEGALVSAGLINLVGGNLSPSDPMENMLNSREDEPLDLSOPAPASTTTLVRE

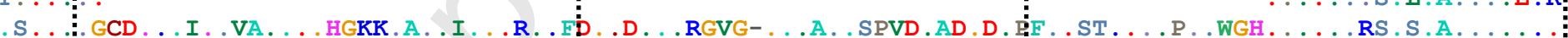

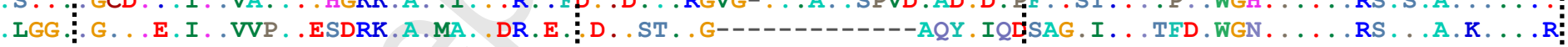
T.... .

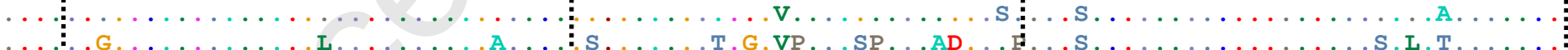
-

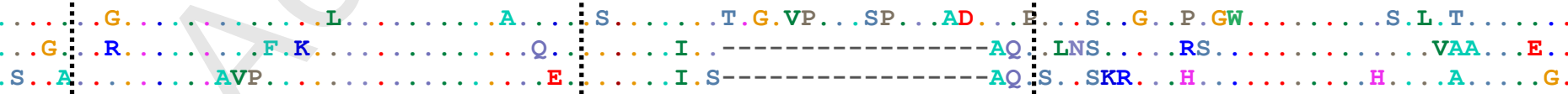

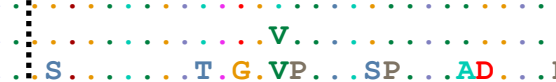
-

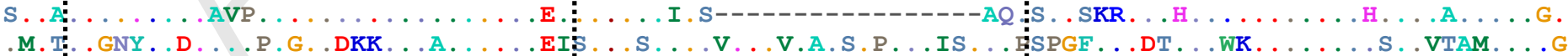
L. 


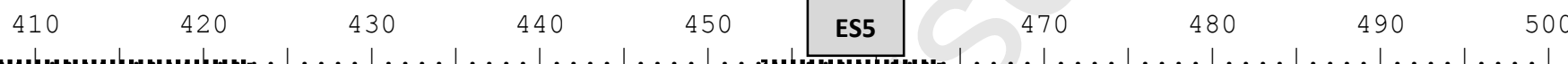

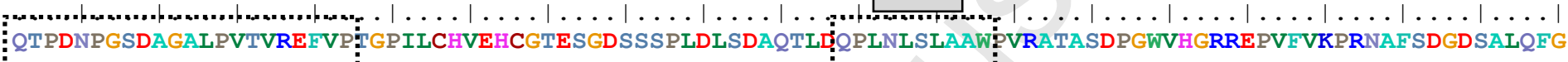

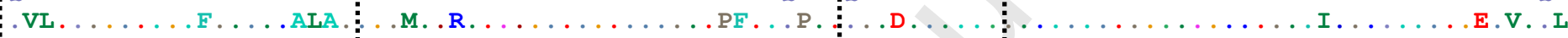

3262

3266

3267

Porcilis

AY588319

DQ864705

GQ461593

AY366525

DQ489311

EU076704 A...D.S.D.PS . .QG . E. .PRL . . . . . . . . V.R .

MSN . SPG.DT , N-D-1

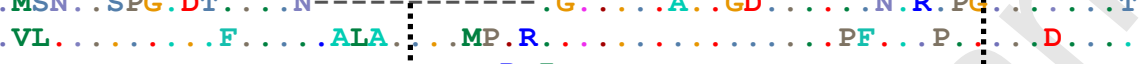

FJ349261

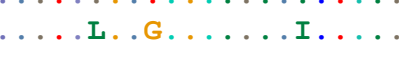

$R$. PR.

- $\ldots \ldots \ldots \ldots \ldots \ldots$

… . . . . . . . . . .

R.PR

-

L..Y. . I . . . . A. . S . IRFH

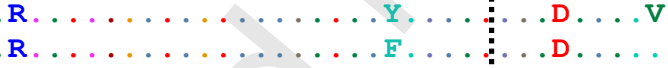

Fin

530

ES6

550

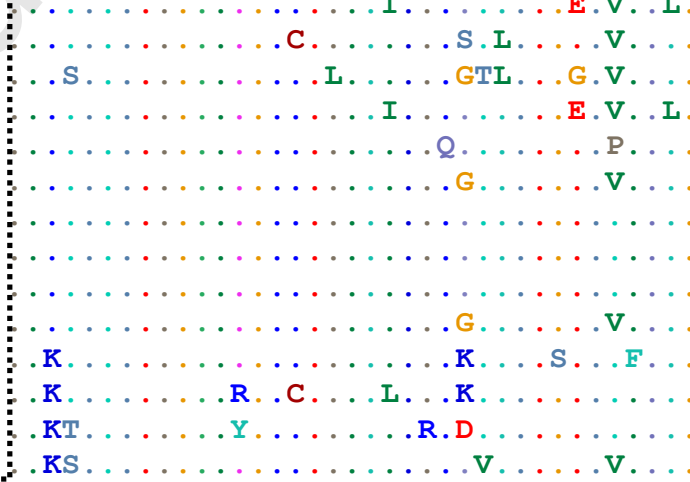

M96262

2982

3249

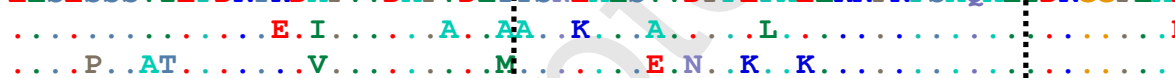

DVHAKIKNRVYEQCLQACEPGSRATPATREWLDKMWDR

3262

3266

3267

Porcilis

AY588319

DQ864705

GQ461593

AY366525

DQ489311

… ....... . . . . . .

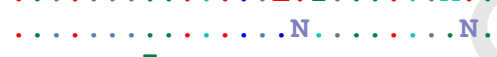

$\ldots \ldots$ I. . . . . . . .

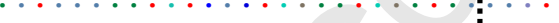

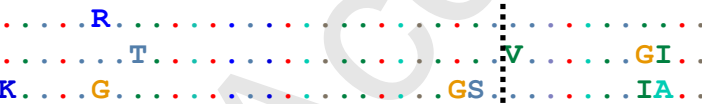

EU076704

........... . TL.A.

A... . . V. . . . . . .

FJ349261

G..................

A...K.S.PR.

$\ldots$

$\ldots \ldots \ldots$ R. . . . R R

. D. . . . . . . .



.

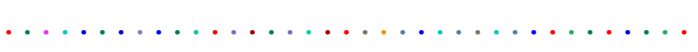

K. . . . .

$\ldots \mathrm{L} \ldots \ldots \mathrm{K} \ldots \mathrm{R}, \mathrm{C}$

KK...R.A. 
\begin{tabular}{llll|llllll}
610 & 620 & 630 & 640 & 650 & ES7 & 670 & 680 & 690 & 700
\end{tabular}

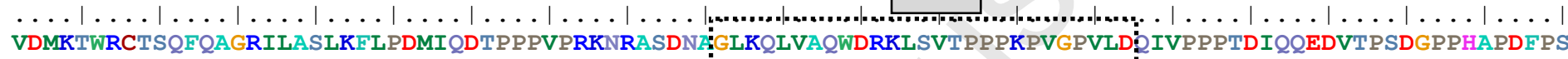

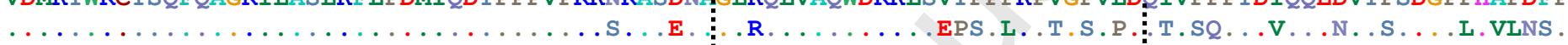

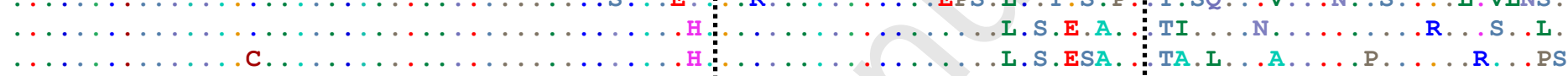

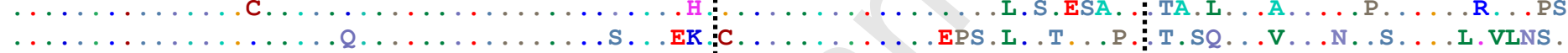

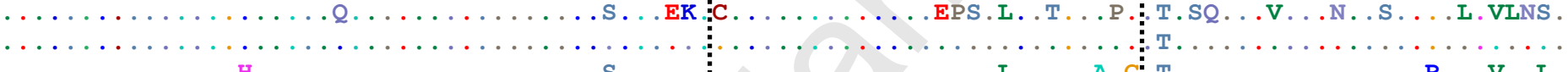

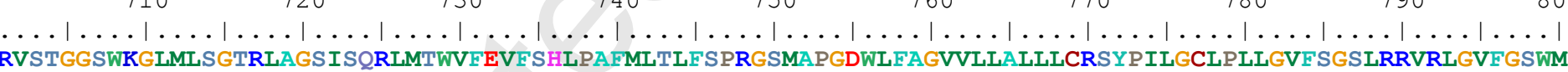

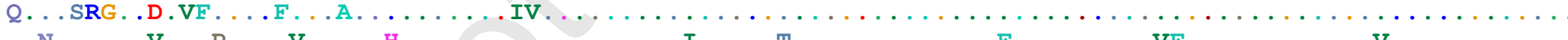

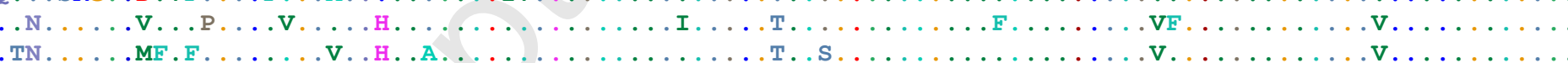

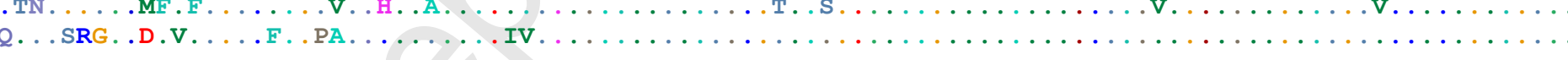

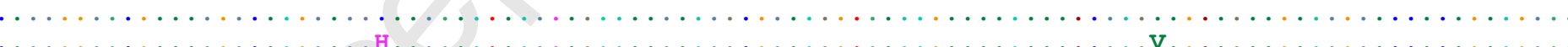

EU076704 D. C .

FJ349261 
$\begin{array}{rrrrrr}810 & 820 & 830 & 840 & 850 & 860\end{array}$ $\ldots$.
AFAVELFSTPSNPVGSSCD HDSPECHAELLALEQROLWEPVRGLVVGPSGLLCVILGKLLG

M96262

2982

3249

3256

3262

3266

3267

Porcilis

AY588319

DQ864705

GQ461593

DQ489311

EU076704

FJ349261

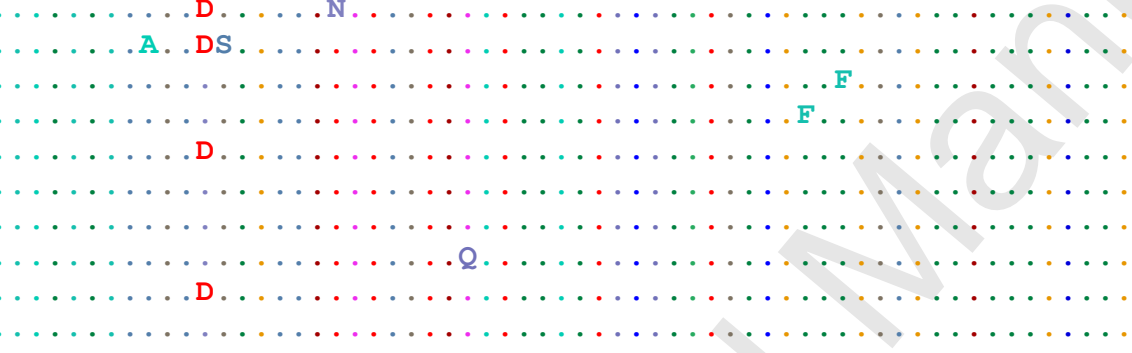


Figure 3. Partial graphic view of the alignment of the predicted amino acid sequences of GP3 of the PRRSV strains examined. The dotted box shows the epitope reported by Oleksiewicz et al. (2000).

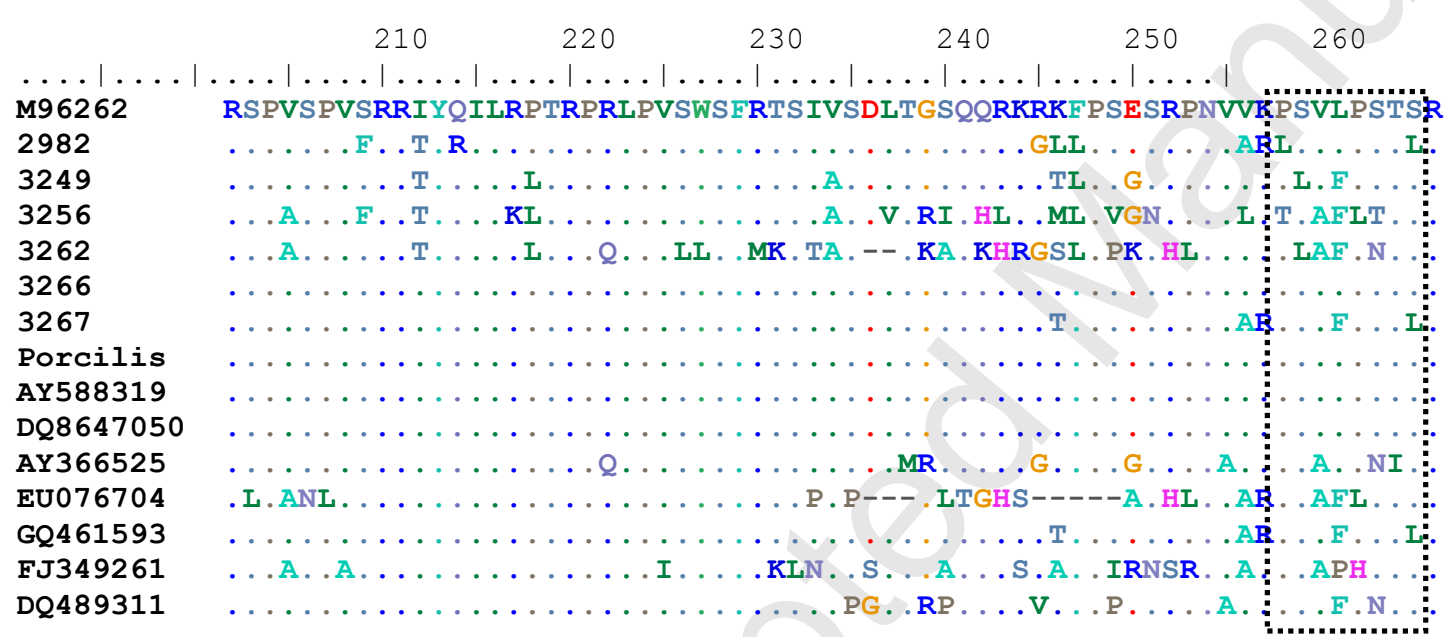


Figure 4. Graphic view of the predicted amino acid sequences of GP4. The dotted box show the location of the neutralization epitope reported by Meulenberg et al. (1997).

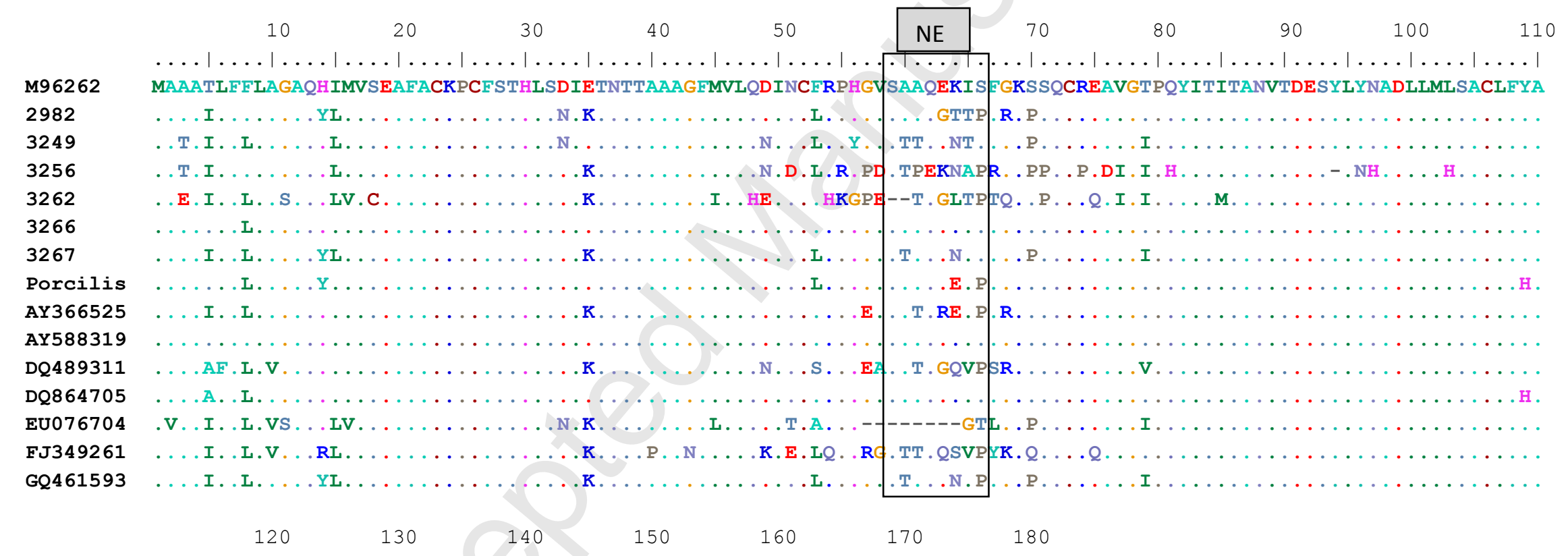

M96262

2982

3249

3256

3262

3266

3267

Porcilis

AY366525

AY588319

DQ489311

DQ864705

EU076704

FJ349261

GQ461593

$\ldots|\ldots| \ldots|\ldots| \ldots|\ldots| \ldots|\ldots| \ldots|\ldots| \ldots|\ldots| \ldots|\ldots| \ldots|\ldots| \ldots \mid \ldots$ SEMSEKGFKVIFGNVSGVVSACVNFTDYVAHVTQHTQQHHLVIDHIRLLHFLTPSAMRWATTIACLFAILLAI

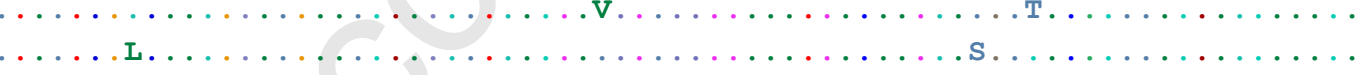

$$
\begin{aligned}
& \text {.V. .D-.NE. }
\end{aligned}
$$

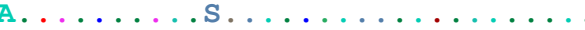

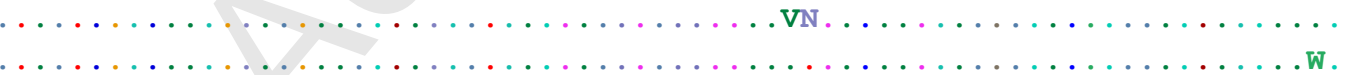

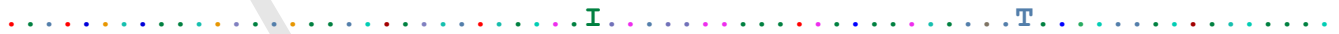

$$
\begin{aligned}
& \text { พ }
\end{aligned}
$$$$
\ldots \ldots \ldots \ldots \ldots
$$ 
Figure 5. Topology of the synonymous-non synonymous substitution rate in codons (ORFs1-7) of 15 European type PRRS strains. Annotation in the lower part of the graph indicates topology of each ORF. Boxes located in the center show the location of non structural proteins in ORF1a/1b. Y-axis show the rate of synonymous-non synonymous substitutions per codon; $X$-axis show the number of codons starting at nsp1.

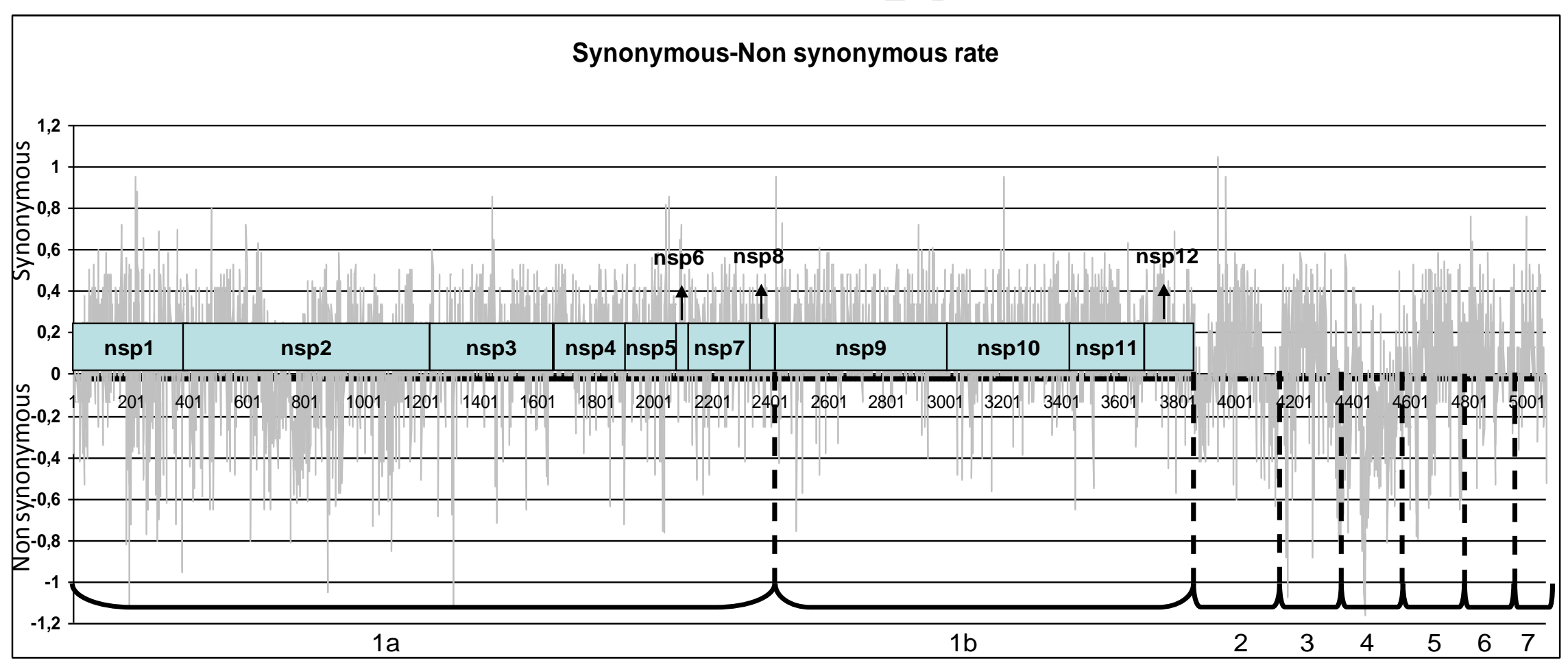


Figure 6. Mid-point rooted tree based on the genomic sequence of nsp9, on full ORFs1-7 sequences and ORF5 and ORF7 PRRSV sequences. Bootstrap values are shown in the branches.

\section{Full ORF1-7}

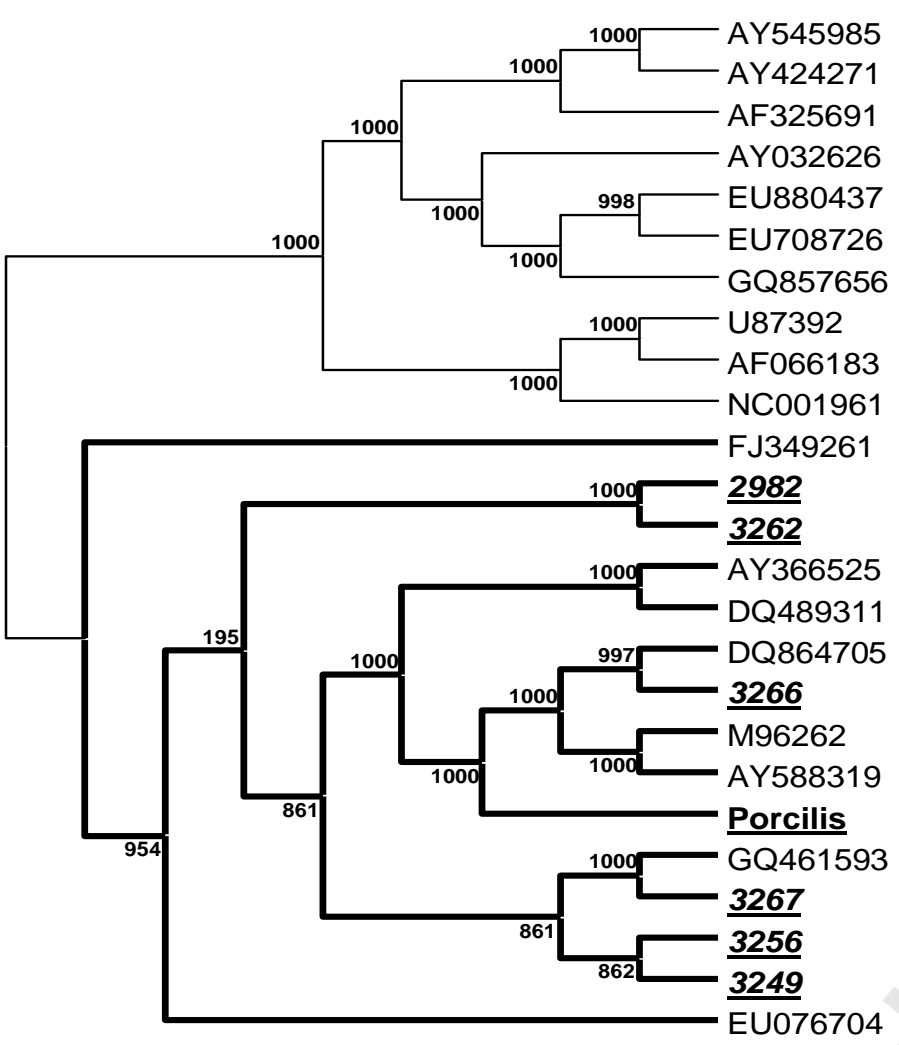

Nsp9

\section{ORF5}

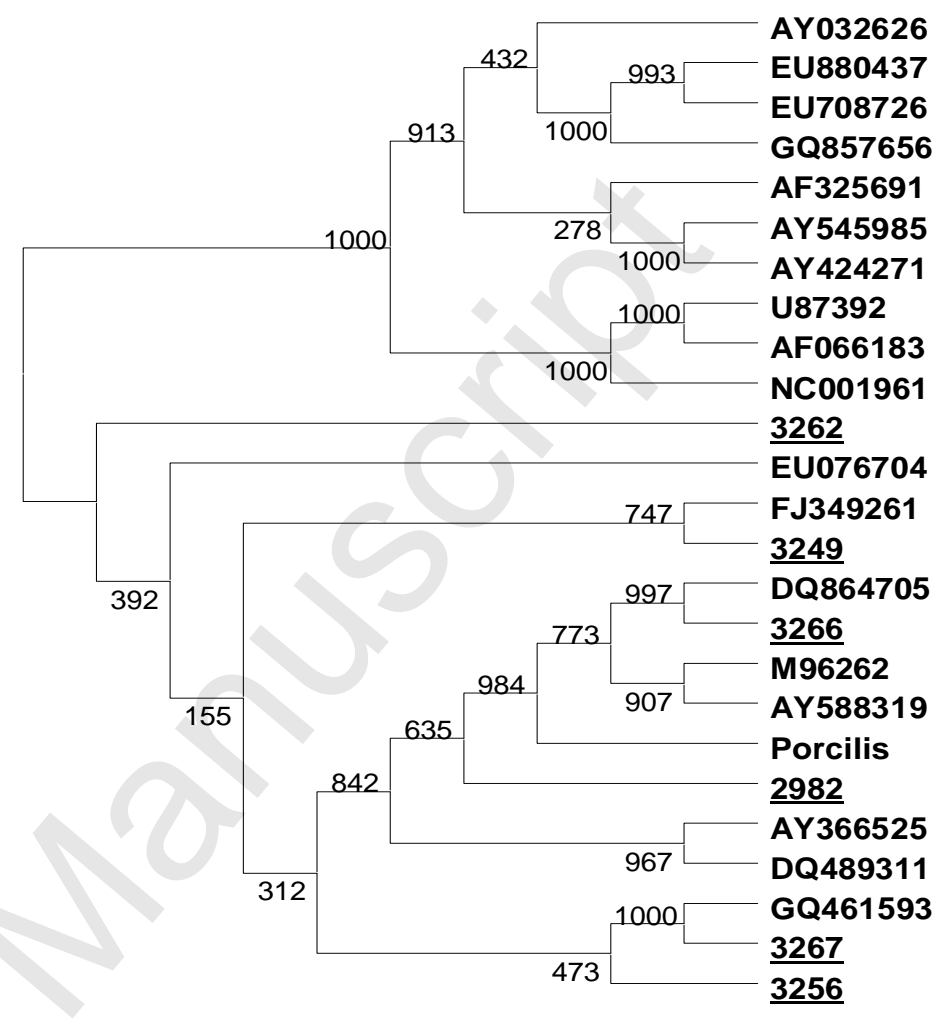

ORF7

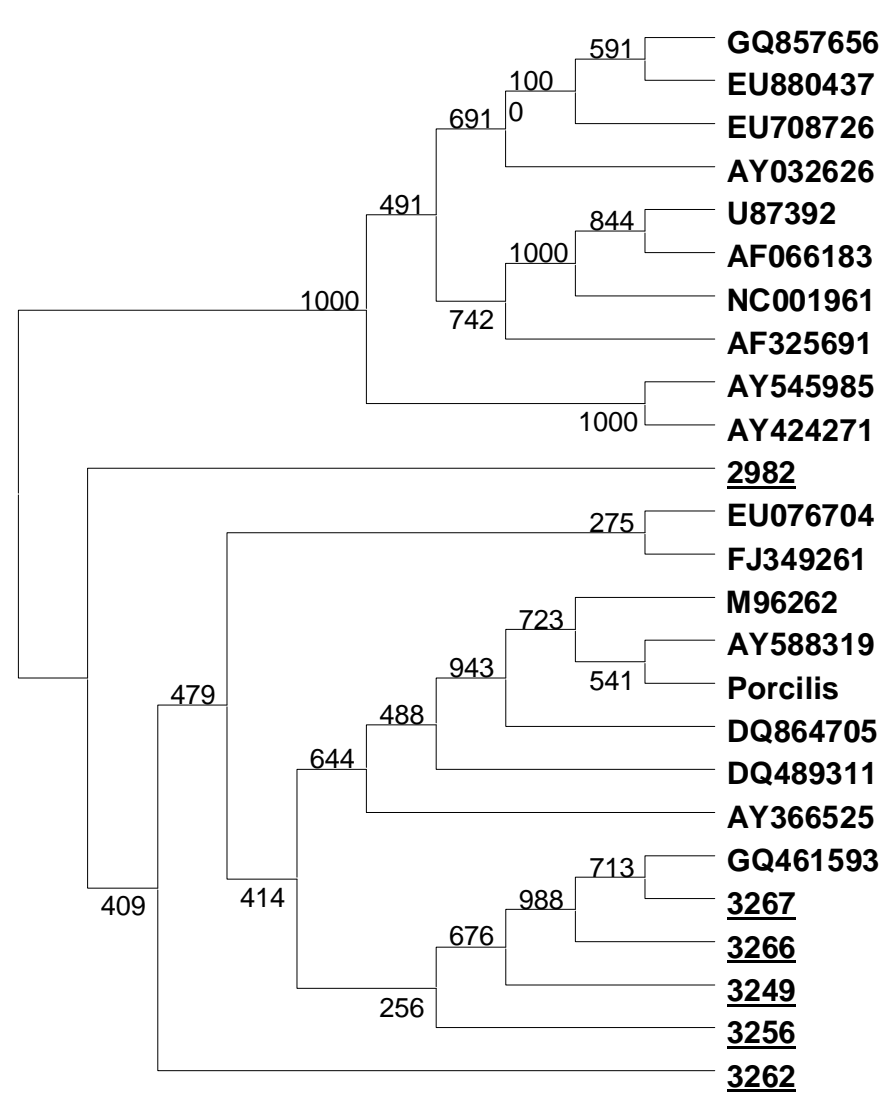

